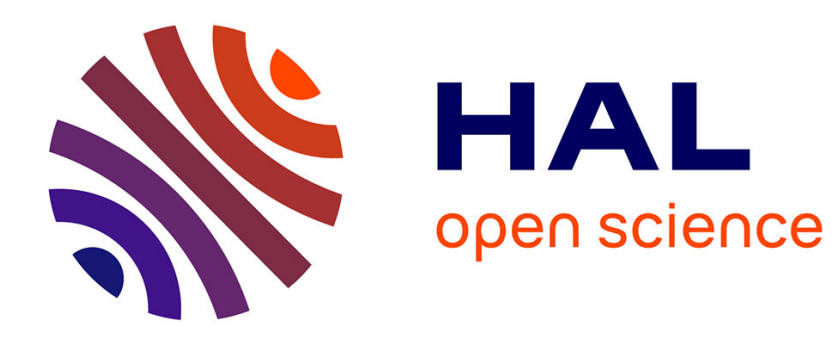

\title{
Pollution Haven and Corruption Paradise
}

Fabien Candau, Elisa Dienesch

\section{To cite this version:}

Fabien Candau, Elisa Dienesch. Pollution Haven and Corruption Paradise. 2016. hal-01847939

\section{HAL Id: hal-01847939 \\ https://hal.science/hal-01847939}

Preprint submitted on 24 Jul 2018

HAL is a multi-disciplinary open access archive for the deposit and dissemination of scientific research documents, whether they are published or not. The documents may come from teaching and research institutions in France or abroad, or from public or private research centers.
L'archive ouverte pluridisciplinaire HAL, est destinée au dépôt et à la diffusion de documents scientifiques de niveau recherche, publiés ou non, émanant des établissements d'enseignement et de recherche français ou étrangers, des laboratoires publics ou privés. 


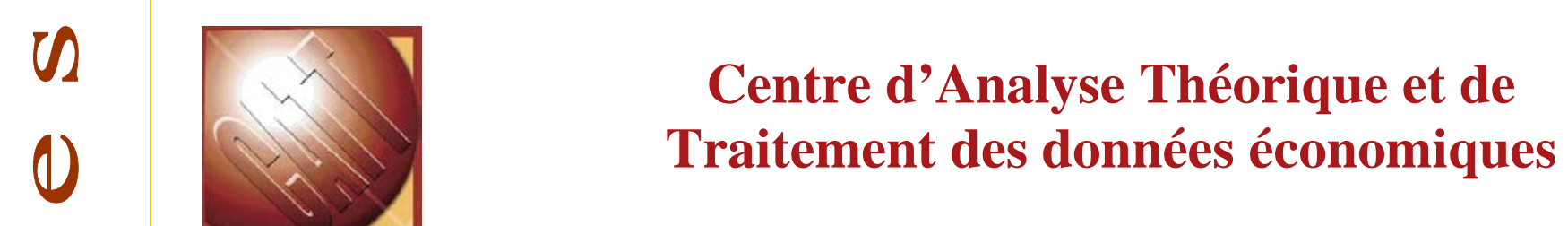

0

Fabien CANDAU

Elisa DIENESCH

POLLUTION HAVEN

AND

CORRUPTION PARADISE 


\title{
Pollution Haven and Corruption Paradise
}

\author{
Fabien Candau (UPPA, CATT)* \\ Elisa Dienesch (Sciences Po Aix, CHERPA) ${ }^{\dagger}$
}

October 4, 2016

\begin{abstract}
In this paper, we propose a new perspective to analyze the impact of institutions, environmental standards, and globalization on relocations of polluting firms in countries with lax environmental regulation (called pollution havens). Via a simple theoretical extension from the Economic Geography literature, we characterize the main features of pollution havens: a good market access to high-income countries and corruption opportunities. Using structural and reduced-form estimations, we analyse these determinants by exploiting a unique database on the number of European affiliates located abroad. A $1 \%$ increase in access to the European market from a pollution haven fosters relocation there by $0.1 \%$. We also find that corruption in these countries lowers environmental standards, which strongly attract polluting firms: a $1 \%$ increase in this indirect effect of corruption fuels relocation by $0.28 \%$. We test the economic significance of these empirical findings via simulations. The protection of the European market (e.g., a carbon tax on imports) to stop relocations to pollution havens must be high (a decrease of the European market for Morocco and Tunisia equivalent to 13\%) not to say prohibitive (31\% for China).
\end{abstract}

Keywords: Multinational firms; Environmental Regulation; Europe; Corruption; Market Access, Trade.

JEL: F12;Q5;Q53

*Corresponding author: fabien.candau@univ-pau.fr

${ }^{\dagger}$ We thank Simone Bertoli, Antoine Bouët, Pierre-Philippe Combes, Matthieu Crozet, José de Sousa, Carl Gaigné, Michaël Goujon, Jacques Le Cacheux, Serge Rey, Frédéric Robert-Nicoud, François-Charles Wolff for their attentive reading and comments. We also thank seminar and conference participants at CERDI, ETSG, U. Geneva, U. Toulon. 


\section{Introduction}

"Although existing studies suggest little or no evidence of industrial relocation, arguments over pollution havens persist. Why?" Eskeland and Harrison (2003)

In the early 2000s, it was quite common to dismiss the existence of pollution havens by underscoring that there is no evidence of this hypothesis. Laxer environmental standards could not significantly explain the location choice of polluting plants. However, failure to reject the null hypothesis does not ensure that the null hypothesis is always true, and a growing number of articles have successfully found this effect for inward, outward, and outbound foreign direct investments (FDI) in the context of the United States. 1 . While the discussions on PHH have thus far relied to a great extent on data from the United States, a similar analysis for Europe has been neglected. This is surprising since the European environmental policy has been quite active over the past few years. Furthermore, Europe and its neighborhood have changed; post-communist economies (central and eastern European countries, Russia, and China) as well as partners in Maghreb (e.g., Tunisia and Morocco) have now reached an intermediate level of bad governance - good enough to conduct business (e.g., without risk of expropriations) but still poor enough to allow businesses to pollute with unspoken license. Lastly, access to the European market has been vastly improved thanks to multilateral, regional, and preferential trade agreements, which make relocation outside Europe and/or at its periphery less costly. As a result, Europe is the perfect field to analyze the PHH and its interaction with governance and trade integration. ${ }^{2}$

Regarding the literature on the PHH, this hypothesis has been viewed as a "popular myth" (Smarzynska Javorcik and Wei, 2003) for various reasons. The main two arguments are that environmental costs represent only a small part of the costs being considered when deciding where to locate factories, and that polluting industries are capital-intensive meaning that

\footnotetext{
${ }^{1}$ Excellent considerations of the literature have been made by Brunel and Levinson (2013), who discuss measures of environmental regulatory stringency, and in Millimet and Roy (2013), who present empirical tests of the PHH, as well as the econometric biases and methodological issues for this type of analysis. Lastly, Rezza (2014) presents a meta-analysis.

${ }^{2}$ While data on the United States have been intensively used to analyze the PHH, studies on Europe have been scarce. Only a handful of countries such as Norway, France, and Germany (Ben Kheder and Zugravu, 2012; Rezza, 2013; Wagner and Timmins, 2009) and the United Kingdom (Manderson and Kneller, 2009; Martin, de Preux, Wagner, 2014) have been analyzed in this regard. Cave and Blomquist (2010) and Jug and Mirza (2010) are are among the few researchers who have analyzed the PHH in the European context. Such a scale of analysis is important because environmental regulation and tariffs are typical areas in which the European Union has the authority to devise public policies. Related to the PHH, Brunel (2016) determines that the cleanup of EU manufacturing is more due to improvements in production techniques than to offshoring, without finding support for the PHH in Europe. However, all these studies differ greatly from our analysis, since their authors only analyze imports of polluting goods and compositional changes in production, and not relocation of firms.
} 
they are the comparative advantage of industrialized economies and are hard to relocate. Countries with stringent environmental rules have advantages that overtake the environmental cost (e.g. better infrastructures, larger market size, better endowment in human capital etc) while countries with lax environmental standards have repulsive characteristics such as poor institutions and bad governance which represent a cost for multinational firms. However, by improving market access to developed countries from pollution havens, globalization erodes the advantage of locating plants close to the point of consumption. Furthermore, a pollution haven can be "a dirty secret" in the sense that bribes may allow polluting firms to obtain laxer environmental rules in the law and/or in its enforcement.

Our model, which is based on Fujita and Thisse (2006), displays these effects. When bad governance has no effect on environmental standards, corruption is only a cost for multinational firms and deters relocation to pollution havens. By contrast, the $\mathrm{PHH}$ is always verified under what we call the "Corruption Paradise Hypothesis," hereafter CPH, which assumes that corruption allows lax environmental standards. Under this hypothesis, corruption may be an opportunity for a firm, through its indirect impact on regulation. The model also explains why the existence of $\mathrm{PHH}$ is hard to confirm since it depends very much on market access; explaining that no relocation is observed until a critical threshold of trade integration is reached $!^{3}$ In order to operate in the largest markets, firms agree to pay the highest environmental costs, but if these costs are excessive, they move out of their "green fortress," particularly if they can secure access to consumers from a peripheral location and follow laxer environmental standards 4

Market access is thus a central variable to understand the reason behind the change in locations of firms. To conduct the empirical analysis, we use our theoretical model to measure this concept. In theory, market access is the sum of demands weighted by trade costs. Empirically, a structural trade gravity equation is estimated, that is bilateral trade flows are regressed on distances, exporter and importer dummies to capture bilateral trade costs and market characteristics. This gravity equation is estimated for each industry and each year, and the parameter estimates are used to calculate multilateral market access for each country in each industry. Then, this variable is used to explain location choice of foreign-controlled enterprises, originating from European countries and located in 148 destination countries in 2007, 2008, and 2009.

\footnotetext{
${ }^{3}$ This result is supported by Wagner and Timmings (2009) who find that once agglomeration economies are taken into account, robust evidence of a pollution haven effect for the outward FDI flows of the German chemical industry can be detected. See also Ederington, Levinson and Minier (2003).

${ }^{4}$ To our knowledge, only Zeng and Zhao (2009) provide a similar result with a different model, in which the manufacturing sector generates cross-border pollution that reduces the productivity of the agricultural sector.
} 
We regress the number of European affiliates on bilateral access from the destination towards the origin, and on market access from the origin country and from the destination.5 First, the results reveal a positive effect of the bilateral market access offered by each European member. We also find a positive effect of market access from the destination (European partners) towards the rest of the world, and a negative effect of market access from European countries themselves. Thus, firms are motivated to reach new markets through the market potential offered by the partner while a good market access from Europe retains activities. This is a multilateral gain provided by the destination. Relocation is also clearly motivated by the market potential offered by European nations themselves in their own markets, matching the fragmentation process and the need to re-import cheaper inputs from abroad.

Various articles have contributed towards understanding the impact of trade liberalization on the specialization and economic behavior of multinational firms, ${ }^{6}$ and many others have demonstrated the significance of the market access towards explaining various economic variables..$^{7}$ However, our analysis on the impact of market access on relocation of polluting firms is novel to the literature.

The literature on corruption and relocation of dirty firms is more developed. Damania, Fredricksson and List (2003), in particular, find evidence that corruption reduces the stringency of environmental policies. We go a step further by showing that this indirect effect attracts polluting firms. Our result is thus related to that of Cole and Fredriksson (2009) who are the first shed light on institutions with poor environmental governance, by observing that pollution havens are more likely to occur in countries having institutional structures with few legislative units (e.g., parliaments, congress, government parties, prime minister, and president). While these authors' main interest lies in assessing whether foreign firms that lobby and bribe host country governments succeed in obtaining laxer environmental regulations owing to the characteristics of the country's political institutions, we aim to capture the pros and cons of corruption for polluting firms. Instead of analyzing the net effect of bad governance, we estimate the direct and negative effect of corruption, as well as its indirect and profitable effect.

Challenging the potential endogeneity of environmental regulation and the ambiguous role of corruption on location choices with an original two-step procedure, 8 we find evidence of the

\footnotetext{
${ }^{5}$ The estimator used is a zero-inflated negative binomial model, which is particularly adapted to count data, and deals with the excess of zeros and overdispersion, characterizing our data set.

${ }^{6}$ See, for example, Copeland and Taylor (2003), and Ederington, Levinson and Minier (2005)

${ }^{7}$ Redding and Venables (2004) published a seminal paper analyzing the impact of market access on income per capita. Other studies have followed analyzing wages (Hering and Poncet, 2010), location choices of firms (Amiti and Javorcik, 2008) and individuals (Candau and Dienesch, 2015).

${ }^{8}$ The environmental standard is first regressed by historical levels of regulation, considered as our instrument and by corruption.
} 
existence of the CPH: corruption indirectly increases the number of relocations of polluting firms to pollution havens. ${ }^{9}$

Finally, to evaluate the economic significance of our results and to formulate policy implications, we simulate scenarios of environmental policy cooperation. The results show that the harmonization of environmental norms in Europe could reduce relocation by $6 \%$. We also evaluate the equivalent variation of market access needed to get more stringent environmental standards for some partners without affecting their attractiveness. For instance, we find that given the current level of relocation, a carbon tax reducing the European market by $13 \%$ for firms operating in the Maghreb erases the advantage provided by the gap in environmental regulation.

The paper proceeds as follows. Section 2 outlines the theoretical model and explores the relationship between trade, regulation and choices of location. Section 3 presents the overall empirical strategy, and Section 4 reports the results. In Section 5, we conduct simulations using previous estimates. Section 6 concludes the paper.

\section{Theoretical model}

To analyze the evolution of the supply chain in the case of pollution havens, our model is a slightly modified version of Fujita and Thisse's (2006) mode ${ }^{10}$ in order to improve the assessment of the complementarity between relocation of firms to pollution havens and trade integration. In this model of monopolistic competition and increasing returns, trade flows and capital flows are not always substitutes. This allows us to arrive to novel results concerning the location choices of polluting firms in comparison with neoclassical models (see Anderson, 2005, for a discussion). We start the description of this model by individual preferences.

Each individual consumes a basket $M$ of different industrial varieties $z$ and an agricultural good $A .11$ The utility function is represented by a Cobb-Douglas Constant Elasticity of

\footnotetext{
${ }^{9}$ All the results are robust to a number of checks, identification tests, and weak IV tests.

${ }^{10}$ Fujita and Thisse (2006) analyze the evolution of the international fragmentation of supply chains due to wage differentials in the context of trade and coordination integration between the North and the South. A simple change in the cost function of this model is a good fit with the issue at hand. Instead of considering the wage differential (weighting on the variable costs, as done by Fujita and Thisse, 2006), we analyze how firms slice up their supply chain in response to international gaps in environmental standards and bad governance.

${ }^{11}$ We do not introduce disutility from consuming the industrial goods, which are also the polluting goods, mainly because we are not interested in the welfare impact of pollution or changes in consumption. Such an introduction is easily accomplished with an additive term (as done by Markusen et al., 1995), and it is interesting to analyze the welfare impact of the relocation of polluting firms in cases of global and/or local pollution, and when "not in my backyard" policies prevail.
} 
Substitution (CES) utility function:

$$
U=M^{\mu} A^{1-\mu}, M=\left[\int_{0}^{n} q(z)^{\frac{\sigma-1}{\sigma}} d z\right]^{\frac{\sigma}{\sigma-1}} \mu \in[0,1], \sigma>1
$$

where $n$ is the number of varieties consumed, $q(z)$ is the demand of a variety $z$ and $\sigma$ is the constant elasticity of substitution among these varieties. A share $\mu$ of nominal income, denoted as $Y$, is spent on manufacturing, and $1-\mu$ is spent on the agricultural product. The budget constraint is then given by $P M+p_{A} A=Y$, where $p_{A}$ is the price of the agricultural good and $P$ the price index of varieties:

$$
P=\left[\int_{0}^{n} p(z)^{1-\sigma} d z\right]^{\frac{1}{1-\sigma}}
$$

with $p(z)$ being the price of a typical variety $z$. The total demand to a firm producing a variety $z$ is then given by:

$$
q(z)=\mu Y P^{\sigma-1} p(z)^{-\sigma}
$$

Varieties are exchanged between countries under transaction costs which take the form of iceberg costs denoted by $\tau$. The agricultural good is costlessly traded between countries, and its price is the same everywhere. This good is the numéraire and its price is set to unity. Each firm has one headquarters (HQ) and one plant. Skilled workers are employed at the HQs and unskilled workers, at the plants. The aim of this paper is to analyze the location choice of these plants. The model is analyzed under a condition ensuring the agglomeration of HQs/skilled-workers in some countries (more details on this condition appear below). This concentration of the demand represents an agglomeration force with regard to plants' locations, and goods are produced near the points of demand allowing savings on trade costs. In opposition to this effect, we introduce a dispersion force by considering that environmental standards are stricter in these rich markets. Lastly, to take into account that pollution havens can be repulsive for firms because of inefficient institutions, we consider corruption costs. Formally, the total cost of producing $q$ units of a typical manufactured goods varies according to the location of its HQ and plant in country $i$ or $j$ :

$$
T C_{i j}(z)=c_{j}+f_{i} w_{i}^{H}+v_{i} e_{j} w_{j}^{L} q(z), \quad z \in[0, n], c_{j} \in[0,1], e_{j} \geqq 1
$$

with $j=i$ for national firms, that is, firms that cluster HQs and plants in the same country, and $i \neq j$ for multinational firms that spatially unpack factories and offices. $f$ and $v$ represent the requirement of unskilled and skilled labor determined by the HQ in $i$. Concerning 
environmental standards, $e_{i}$, we assume that they affect the variable costs of production. This is a classical assumption considering that the expenditures on control and monitoring equipment necessary to bring a plant into environmental compliance varies with production. In addition, we assume that the fixed cost of production, denoted as $c_{i}$, bears corruption costs that vary across countries. This fixed cost can be viewed as the number of procedures, amount of time, and bribes that a firm must bear before it can operate legally. These costs of entry were first documented by Djankov, La Porta, Lopez-de-Silanes and Shleifer (2002) and have been used in various studies as a proxy for the bureaucratic and corruption-related costs of starting a business. 12

Under the assumptions of Dixit-Stiglitz monopolistic competition, by maximizing profits, a domestic firm sets a single free-on-board (f.o.b) price, $p_{i}^{*}(z)=w_{i}^{L} \sigma v_{i} e_{i} /(\sigma-1)$, while a multinational firm with its HQ in $i$ and its plants in $j$ sets the factory to $p_{j}^{*}(z)=w_{j}^{L} \sigma v_{i} e_{j} /(\sigma-$ $1)$. Under iceberg trade costs, $\tau_{i j}$, the sale prices in different countries are $p_{i j}^{*}(z)=\tau_{i j} p_{i}^{*}(z)$. Thus, prices differ spatially owing to reasons of geography (trade costs), production efficiency, and environmental standards.

Using the demand expressed by (3), prices and trade costs, the equilibrium profit of a firm clustering its HQ and plant in $\mathrm{i}$ is given by:

$$
\pi_{i i}^{*}=p_{i}^{1-\sigma} M A_{i}-c_{i}-f_{i} w_{i}^{H}, \quad i \neq j
$$

with

$$
M A_{i}=M A d_{i}+M A f_{i}, \quad i \neq j
$$

where

$$
M A d_{i}=\frac{Y_{i}}{P_{i}^{1-\sigma}} \tau_{i i}^{1-\sigma}, M A f_{i}=\sum_{j} M A b_{i j}, \quad M A b_{i j}=\frac{Y_{j}}{P_{j}^{1-\sigma}} \tau_{i j}^{1-\sigma}, i \neq j
$$

The term $M A_{i}$ is the sum of distance-weighted market capacities, and includes local sales, $M A d_{i}$ which refers to domestic market access and $M A f_{i}$ which is the total demand of consumers located abroad. This foreign market access is the sum of bilateral market access $M A b_{i j}$.

The profit at equilibrium of a multinational firm is:

$$
\pi_{i j}^{*}=p_{j}^{1-\sigma} M A_{j}-c_{j}-f_{i} w_{i}^{H}
$$

\footnotetext{
${ }^{12}$ In a previous version of this paper, we conducted the analysis assuming that environmental standards affect the fixed cost while corruption was assumed to represent a variable cost. All the results were identical.
} 
Thus the fragmentation decision of a firm, based on a comparison of $\pi_{i i}^{*}$ and $\pi_{i j}^{*}$, depends on market access from $i$ and $j$ as well as corruption. Since the factory price of each variety varies according to environmental norms, these standards are one of the most significant determinants of the market potential of a country. The other obvious and crucial elements of MA are trade costs (including behind the border policies, and transportation, all other factors affecting $\tau$ ) and the size of each market ( $Y / P$ in real terms).

So far, we have considered the HQ to be agglomerated in country $i$, while the plants are located in $i$ or $j$ depending on $\pi_{i i}$ and $\pi_{i j}$, but the free-entry decision implies that the HQ can also be created in $j$. Thus, at equilibrium, we have to verify that:

$$
\max \left\{\pi_{i i}^{*}, \pi_{i j}^{*}, \pi_{j i}^{*}, \pi_{j j}^{*}\right\}=0 .
$$

While the empirical literature analyzing the impact of the market access on profits, wages and location choices ${ }^{13}$ begins directly with these expressions (in particular (5), (6), and (7)), we go one step further by resolving the model in order to better understand how environmental norms, trade integration and bad governance affect location choices.

\section{$2.1 \quad$ Results}

We consider the model with two countries, North and South, designated with subscripts $N$ and $S$ respectively. Let us assume for now that all the HQs/skilled-workers are agglomerated in the North. We also consider that problems of bad governance are the worst in the South, that is, $c_{S}>c_{N}$, while environmental norms are stricter in the North, that is, $e_{N}>e_{S}$. There are skilled and unskilled workers in the North and only unskilled workers in the South. Then, incomes are given by:

$$
Y_{N}=H w_{N}^{H}+w_{N}^{L} L_{N}, Y_{S}=w_{S}^{L} L_{S}
$$

where $L$ and $H$ are the number of unskilled and skilled workers that earn $w^{L}$ and $w^{H}$. Next, we normalize the total population of skilled and unskilled workers to one $\left(H=1, L_{N}+\right.$ $\left.L_{S}=1\right)$. The fixed requirement of skilled worker to produce one variety is also set to one everywhere, $f_{N}=f_{S}=1$.

The profit of a firm that keeps its plants in the North and those of a multinational firm that

\footnotetext{
${ }^{13}$ See Head and Mayer (2011) for a survey.
} 
slices up its supply chain are given by:

$$
\begin{aligned}
\pi_{N N} & =\frac{\mu}{\sigma n}\left(\frac{Y_{N}}{s_{N}+\phi s_{S} \zeta}+\phi \frac{Y_{S}}{\phi s_{N}+s_{S} \zeta}\right)-c_{N}-w_{N}^{H} \\
\pi_{N S} & =\frac{\mu}{\sigma n} \zeta\left(\phi \frac{Y_{N}}{s_{N}+\phi s_{S} \zeta}+\frac{Y_{S}}{\phi s_{N}+s_{S} \zeta}\right)-c_{S}-w_{N}^{H}
\end{aligned}
$$

with $\zeta \equiv\left(e_{N} / e_{S}\right)^{\sigma-1}$ being the relative environmental norm for the north (when $\zeta=1$ there is no differential in environmental standards), and $\phi \equiv \tau^{1-\sigma}$ being the degree of trade openness $\left(\phi=0\right.$ indicates a situation of autarky and, $\phi=1$, free trade). Lastly, $s_{N}=n_{N} / n$ is the share of firms localized in the North. The demand of skilled labor in this economy is given by $n f$, and the supply of skilled workers by $H$, which gives when the labor market clears the mass of firms is $n=H / f$. Upon normalization, we get $n=1$ which means that $s_{S}=1-s_{N}$.

Two effects drive these expressions. On the one hand, large markets generate more profits and attract plants because firms find significant outlets there (i.e., market-size effect). In this model, the North always has the largest market due to the presence of skilled workers, and consequently, it is intrinsically attractive. On the other hand, the concentration of plants exacerbates local competition and fosters a dispersion of activities (i.e., the market-crowding effect).

Resolving the equilibrium conditions $\pi_{N N}=\pi_{N S}$ with $c_{S}=c_{N}=0$ yields an explicit expression of the share of plants:

$$
s_{N}^{*}=\frac{\zeta}{\zeta-\phi} \frac{2 \zeta \phi-1-\phi^{2}-\frac{\mu}{\sigma}\left(1-\phi^{2}\right)}{2(\zeta \phi-1)}
$$

which leads us to the first result.

Proposition 1 (Pollution Haven): Assume any given positive value of trade costs and no corruption. When the gap in environmental regulation is small enough, all plants are located in the North. When this gap increases, relocation of plants increases monotonically until full agglomeration is reached in the pollution haven.

Proof. Differenting 13 yields:

$$
\frac{\partial s_{N}^{*}}{\partial \zeta}=-\frac{N U M}{2(\zeta-\phi)^{2}(\zeta \phi-1)^{2}}
$$


as the denominator is always positive we focus on the numerator $N U M$, given by:

$$
N U M=\phi\left[b\left(1-\zeta^{2}\right)\left(1-\phi^{2}\right)+(1-\zeta \phi)^{2}+\phi(\phi-2 \zeta)+\zeta^{2}\right]
$$

with $b=\mu / \sigma$ (it is noteworthy that $b<1$ because $\mu<1$ and $\sigma>1$ by definition). Observing that NUM can be upward-concave with respect to $\zeta$ and resolving $\partial N U M / \partial \zeta=0$ for $\zeta$ gives a unique solution: $\underline{\zeta}=\frac{2 \phi}{1-b+\phi^{2}(1+b)}$

$N U M$ attains its minimum at $\underline{\zeta}$ and this minimum is positive $\left(N U M(\underline{\zeta})=\frac{\left(1-b^{2}\right) \phi\left(\phi^{2}-1\right)^{2}}{1-b+\phi^{2}(1+b)}\right)$ because $b=\mu / \sigma<1$. A positive numerator entails that the derivative $\partial s_{N} / \partial \zeta$ be negative (see eq. (14)).

Interestingly $\underline{\zeta}$ is also the critical point after which full agglomeration becomes unstable. Indeed, by resolving the equation of agglomeration in the North $s_{N}=1$ with $s_{N}$ given by (13) we can also find $\underline{\zeta}$. We have already shown that for $\zeta>\underline{\zeta}$, there is a gradual relocation of firms from the North to the South. This relocation stops when $s_{N}=0$ and resolving this equation using (13), gives the critical level of $\zeta$ after which there is full agglomeration in the South. This critical value is: $\bar{\zeta}=\frac{1-b+\phi^{2}(1+b)}{2 \phi}$.

We can now consider the full model under different numerical cases (the analytical solutions and parametrization appear in Appendix A) to analyze the effect of trade integration on relocation for a given gap in environmental standards (and vice versa). An important result of this empirical investigation is that relocation responds very differently to trade integration depending to the gap in environmental standards. To illustrate this, Figure 1 presents the Northern proportion of plants, $s_{N}^{*}$, given by 19 with respect to trade integration, $\phi$, for different values of environmental standards 14 .

Three different results are obtained depending on the extent of the gap in regulations and trade integration.

When the gap in environmental standards is considerable, trade openness leads to relocation of firms to the pollution haven. Indeed with trade integration, the size advantage of the North is too weak to retain firms, which flee to the pollution haven owing to the large gap in environmental regulation.

In the reverse case, where the gap in environmental standard is negligible, more integration leads to the agglomeration of all firms in the North. The size of the market is the main determinant of location in that case.

\footnotetext{
${ }^{14}$ The parameters are $\mu=0.4, e_{N}=58.9, c_{N}=0.01, c_{S}=0.02$, and $\sigma=4$. The curve denoted the small gap in environmental regulation is plotted with $e_{S}=57.25$, the intermediate case (dashed line), with $e_{S}=57.02$, and the case denoting the large gap (black line), with $e_{S}=55$. These parameters are briefly discussed in Appendix A.
} 
Lastly, when the size of the gap is intermediate, relocation to the pollution haven is profitable only when trade integration is high enough, i.e. when firms do not lose their market access to the North by relocating activities in the South.

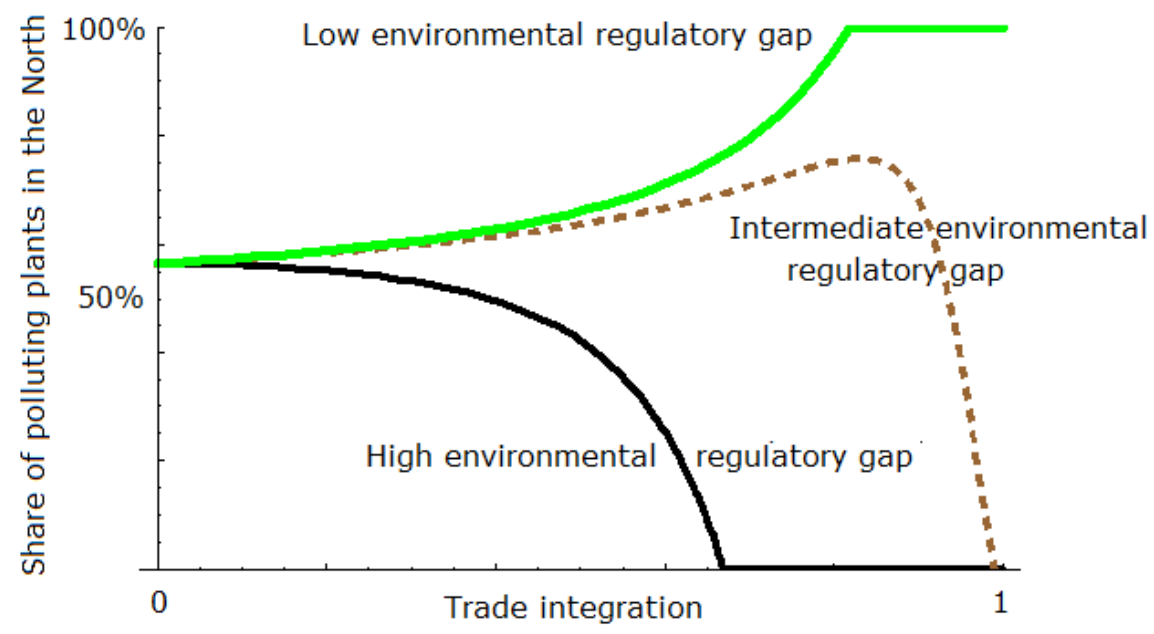

Figure 1: Northern share of plants, openness and environmental regulation

The main result we can derived from this Figure 1 is that the joint effect of environmental standard and trade integration matters. Considered by itself, the gap in environmental standards always has a positive impact on relocation of plants to the pollution haven (Proposition 1) but the simultaneous change in trade costs affects the relationship in an ambiguous way. It is thus necessary to empirically determine whether high-income countries can retain their activities in countries having stringent policies with regards to globalization.

So far we have considered a general case in which bad governance represents a cost for multinational firms when they decide to produce in the South. Therefore, it is trivial to observe that an higher level of corruption in the South (compared to the North) inevitably reduces relocation to the pollution haven (see Eq. (8) ) in our model. While several studies have found that corruption in a host country is indeed a significant deterrent to inward FDI, there are arguments against this proposition concerning polluting firms (e.g. Cole and Fredriksson, 2009). Corruption can "grease the wheels" of the fragmentation process by providing a way to negotiate less stringent environmental standards. We consider this mechanism by assuming that environmental costs can be manipulated by a different kind of corruption, $c^{\mathrm{comp}}$ :

$$
e_{i} \equiv E_{i}-c_{i}^{c o m p}
$$

The gap in the level of corruption and stringency of environmental standards now comple- 
ment each other and attract firms to the South. As a corollary of the previous proposition, consider a "pure corruption paradise," where there is no direct negative cost of corruption $\left(c_{S}=c_{N}=0\right)$ but where in contrast corruption allows reduction in the stringency of environmental standards (the indirect positive effects of $c_{i}^{c o m p}$ ). Then, firms flee to the pollution haven. We summarize this result as follows.

Corollary 1 (Corruption Paradise Hypothesis): If corruption is not a sunk cost, but rather makes environmental standards in the South less stringent, then polluting plants are attracted by bad governance.

The proof of this result is obvious from Proposition 1. In contrast, the overall effect of corruption is less clear, i.e. when $c_{S} \neq c_{N} \neq 0$. Based on numerical simulations, we analyzed what happens when corruption has both a direct negative impact and an indirect positive one, i.e. $c_{i}^{c o m p}=c_{i} \cdot{ }^{15}$ We find a bell-shaped relationship between corruption and relocation. A small gap with regards to corruption, leads to agglomeration in the North, but in the case of a bigger gap, the indirect effect dominates, and multinationals relocate their plants to the South.

\section{Empirical strategy}

\subsection{European outward Foreign AffiliaTes Statistics (o-FATS)}

We base our empirical analysis on an original database that reports all European-controlled enterprises, located abroad. We use the outward Foreign AffiliaTes Statistics (FATS) from Eurostat, covering the period 2007-2010. This unique data set contains the number of affiliates, associated turnover and corresponding number of employees. It is quite exhaustive; the French statistical institute, INSEE ${ }^{16}$ for instance, acknowledges this data set as a complete census of French multinational firms located abroad. Furthermore, while the literature uses data for FDI flows, which by themselves are quite heterogeneous (including mergers, acquisitions, new facilities, reinvested profits, etc.), we focus on foreign-controlled firms that are majority-owned by a single investor or by a group of associated investors acting in concert and owning more than $50 \%$ of ordinary shares or voting rights. As a result, the sample is more homogeneous, especially in terms of capital mobility, which helps us reduce the esti-

\footnotetext{
${ }^{15}$ Not reported here, but available upon request.

${ }^{16}$ L'Institut National de la Statistique et des Etudes Economiques, http://www.insee.fr/fr/themes/document.asp?ref_id=ip1439
} 
mation bias. ${ }^{17}$ The other advantage of this data set is that it fits our theoretical analysis, as it presents the stock of affiliates instead of flows.

The data are recorded at the sector-level (the Statistical Classification of Economic Activities in the European Community, abbreviated as NACE). Notably, 30\% of European affiliates are located in another European union member state, underlying the importance of the single market. The United States is the principal destination of firms controlled by Germany and the United Kingdom. Emerging markets, such as China, India, Brazil, Mexico, Turkey, Argentina and Thailand, are the selected destinations of $16 \%$ of firms located abroad. For instance, Germany is the biggest investor in China. Developing countries are also well represented (expected emerging and eastern countries), accounting for $23.62 \%$ of total affiliates. This mainly includes African countries, which comprise 35 destinations among the 145 available in the data set. Italy is the most active country in Africa, and the Netherlands in South-East Asia. These data are potentially responsible for many zero counts. This issue may induce a severe estimation bias if an appropriate econometric model is not adopted. For this reason, sub-section $(3.2)$ is dedicated to a discussion about the choice of the relevant estimator, to address these data issues.

\subsection{Econometric strategy: choosing the count data model}

As mentioned previously, the dimension of our data set, by origin, destination and industry, implies the presence of null values which need to be treated with the appropriate count data model. Figure (2) Appendix B) illustrates the distribution of the number of European affiliates in foreign markets for the period 2007-2010. This histogram clearly displays a high proportion of zero values, which justifies the use of derived Poisson models. In reality, a basic Poisson model underestimates the probability of zero counts. This excess of zero is a significant and relatively common issue, requiring specific econometric processing, that is, zero-inflated and hurdle models. Such models address the high occurrence of zeros, by assuming that the zeros and positive values do not stem from the same data-generating process.

In our case, we choose zero-inflated models as our core strategy. Although, both models deal with the high occurrence of zeros in the observed data, there is one important distinction in the interpretation of zero counts. In the case of the hurdle model, the process for zeros

\footnotetext{
${ }^{17}$ The diversity in the nature of investments accounted in FDI implies greater heterogeneity in the determinants of location choices, which cannot be efficiently captured by pair dummies and/or common variables of controls leading to over/under estimate the coefficients of our main variables. For instance, firms that are very footlose will not be affected in the same way by corruption than other firms. A restriction on the ownership implies that firms have a more similar behavior in term of mobility.
} 
is not constrained to be the same: a Bernoulli probability governs the binary outcome of zero/nonzero values and the positive realizations are governed by a truncated-at-zero model (Poisson or negative binomial). Conversely, with zero-inflated models, the response variable is modeled as a mixture of a Bernoulli and Poisson (or negative binomial) distribution. Positive values are determined similarly. This option seems the most relevant since location choices are not supposed to be sequential processes. Nevertheless, as there may be some issues, we report alternative estimations based on the hurdle and pseudo-maximum likelihood estimators in Table 10 of Appendix C.

Another distinctive feature of count data is overdispersion, which is observed when the variance is clearly higher than the mean value. To check the presence of overdispersion, we first observe Figure (2, Appendix B), that illustrates intrinsic heteroskedasticity, with variance increasing with the mean value. We report summary statistics in Table (7) Appendix B), showing that the mean number of European affiliates is lower than the variance. Thus, the data are clearly over-dispersed. Following this statement, the econometric treatment needs to be adjusted by replacing the Poisson distribution by the negative binomial distribution, which is a better fit for over-dispersed data. This concern leads us to choose a zero-inflated negative binomial (ZINB) model as the core of our econometric strategy and to compare results with other count data models. Overdispersion tests, such as the likelihood-ratio test are conducted for each regression, and their results add weight to the idea that the Poisson distribution is not appropriate.

This model is estimated by a the maximum likelihood method, consistent with the presence of heteroskedasticity. This estimator is also especially efficient in large samples (Cameron and Trivedi, 1986). As a more effective control for heteroskedasticity, we compute robust standard errors and confront with the bootstrapped standard errors to check the sensitivity of our results.

\subsection{Estimation equation and data}

\subsubsection{Estimation equation}

We estimate the following equation:

$$
\nu_{N S}^{k t}=\exp \left(A+\Phi+\xi+\Omega+\lambda_{N S}+\lambda_{t}+\lambda_{k}\right)
$$

where $\nu_{N S}^{k t}$ is the conditional mean of $s_{N S}^{k t}$, which refers to the number of foreign-controlled firms relocating from a European country $N$ to the destination country S, in industry $k$ at time $t$. The subscript $N$ refers to 25 European countries, while $S$ refers to the 145 recorded 
destinations, including the European ones.

Following the theory, three determinants are included in the regressors, through the following vectors $\Phi$ which refers to market capacities, $\xi$ which isolates the effects of environmental policies and $\Omega$ which is associated with corruption effects. The sizes and contents of these three vectors are described in subsection (3.3.2).

Vector $\lambda_{N S}$ captures the country-pair heterogeneity. Two cases are considered. First, we control for unobserved heterogeneity with the use of a country-pair fixed effect to capture all time-invariant unobservable bilateral factors. This fixed effect may imply a multicollinearity issue and thus an important dummies elimination. To deal with this, we also estimate this equation by introducing a traditional vector of control variables, which is used to reflect tax, economic social differences. ${ }^{18}$ Finally, $\lambda_{t}$ controls for time-specific elements that may affect the number of relocations and $\lambda_{k}$ is an industry fixed effect systematically used to control for unobservable sectorial features. Countries fixed effects may be also introduced but a large part of country heterogeneity is mostly captured by the vector $\Phi$ of market capacities which already rely on country-specific fixed effects. The following subsection presents this in details.

\subsubsection{Core variables and data}

Trade effects and the market access Focusing on market access, the vector $\Phi$ is given by:

$$
\Phi \equiv a_{1} \ln \left(M A b_{S N}\right)+a_{2} \ln \left(M A_{N}\right)+a_{3} \ln \left(M A_{S}\right)
$$

where $M A b_{S N}$ refers to the bilateral market access to $N$ from $S$, while $M A_{N}$ and $M A_{S}$ denote multilateral market access towards $N$ and $S$, in other words towards the origin and destination countries (including Europe) respectively. This index of market access can be decomposed into domestic and foreign shares, so that $M A_{N}=M A d_{N}+M A f_{N}$. In addition to match the theory, these distinctions among trade terms allow us to analyze the mechanism, by which market access affects the location choices of foreign-controlled firms.

More precisely, turning to the index used, one of the central tenets of the Economic Geography is the importance of proximity to consumers, namely, market access which is defined as the distance-weighted sum of the market capacity of surrounding locations, which is obviously affected by trade costs. Based on the theory, our empirical specification includes both domestic and foreign components of market access in the set of determinants of location

\footnotetext{
${ }^{18}$ Are precisely introduced geographic features (distances), cultural and institutional proximity (a dummy for common language), and socio-economic differences (tax incomes as a percentage of the GDP, GDP per capita, and unemployment rates).
} 
choices. Thus, we need to contruct indexes that capture the domestic market access of a country $i$ with $i=N, S$

$$
M A d_{i}=\frac{Y_{i}}{P_{i}^{1-\sigma}} \tau_{i i}^{1-\sigma}
$$

and the foreign market access, with partners $j$

$$
M A f_{i}=\sum_{j} \frac{Y_{j}}{P_{j}^{1-\sigma}} \tau_{i j}^{1-\sigma}, i \neq j .
$$

To do so, we conduct a structural computation of market access, derived from our theoretical model. This structural computation proceeds in several stages. We first estimate a bilateral trade gravity equation to obtain empirical estimates of bilateral trade $\operatorname{costs}\left(\tau_{i j}^{1-\sigma}\right)$ and each country's market capacities $\left(Y_{j} / P_{j}^{1-\sigma}\right)$, which are captured by importer fixed effects. ${ }^{19}$ Then, using these predicted values of trade costs and importer fixed effects, we construct empirical predictions of market access, denoted as $\widehat{M A d_{i}}$ and $\widehat{M A f_{i}}$ following their theoretical specification and noting that $\widehat{M A}_{i}=\widehat{M A d}_{i}+\widehat{M A f}_{i}$.

To our knowledge, this current standard measure of market access has never been used in environmental economics. To measure its impact on relocation at the sectorial level, we conduct this two-step procedure on the disaggregated trade data from UN Comtrade, at the 2-digit level (SITC rev 2.). Particular attention is paid to the establishment of correspondence tables between sector classifications, so as to match the SITC rev 2 classification to the Eurostat NACE rev 120

Environmental policy The vector $\xi$ allows us to isolate the effect of environmental policy on location choices and is given by

$$
\xi \equiv a_{4} \ln \left(E_{N}^{k t}\right)+a_{5} \ln \left(E_{N}^{t}\right)+a_{6} \ln \left(E_{S}^{t}\right)
$$

We exploit both sectorial and country-specific dimensions, by introducing a measure of environmental regulation at the industry level, available for European countries and a global index of environmental policy stringency in the origin and destination countries. In order to

\footnotetext{
${ }^{19}$ Basically, we estimate the following bilateral trade equation for each cross-section:

$$
X_{i j}=\ln \left(\tau_{i j}\right)+F X_{i}+F M_{j},
$$$$
\text { with } \tau_{i j}=\text { dist }_{i j} e^{\text {border }} \text { and } F M_{j}=\ln \left(Y_{j} / P_{j}^{1-\sigma}\right) \text { and } F X_{i}=\ln \left(Y_{i} / P_{i}^{1-\sigma}\right) \text {. }
$$

With regard to the internal transport cost, we follow the existing literature and use $\tau_{i i}=2 / 3 \sqrt{\text { area } / \pi}$. See Appendix (B) for more technical details about this gravity equation estimation.

${ }^{20}$ All the data sources are presented in Table 8 ) of Appendix B.

Correspondence tables are available upon request.
} 
find evidence of the PHH, both $E_{N}^{t k}$ and $E_{N}^{t}$ should be positive and, $E_{S}^{t}$, negative. ${ }^{21}$ Measuring the environmental policy stringency is really challenging and the choice of indicators among several options is usually driven by data availability. A growing number of indicators has been used in the literature, among which we find monetary variables, composite and performance indexes or more direct measures of environmental standards. In order to test the robustness of our results, we employ several measures, starting with a monetary indicator, namely environmental expenditures, measured at the sectorial level in each origin country $\left(E_{N}^{k t}\right) \cdot 22$ The main advantage of using expenditures is to deal with the sectorial diversity in environmental policy, unfortunately, this index is not available for countries outside the E.U.. To measure the environmental regulation of all countries, we have the choice to use a composite index, like the Environmental Performance Index (EPI) data set of Yale University, or a more direct measure of environmental standards. Regarding our empirical strategy, composite indicators (e.g. EPI) have many drawbacks. The main downside is the difficulty to identify the direct and isolated effect of the environmental policy. Such performance indicators are based on outcomes which are actually the product of several policies (in agriculture, energy, infrastructures, etc,.) and not only the result of environmental regulation. This is clearly an identification issue which leads us to only consider this index for a robustness check.

Consequently, for $E_{N}^{t}$ and $E_{S}^{t}$ we suggest to use a direct measure of the regulation on Persistent Organic Pollutants (POPs). These twelve toxic products are chemical substances that persist in the environment. They include pesticides, industrial chemicals and unintentional by-products of industrial processes (such as dioxins and furans). This indicator consists in scoring information on whether countries allow, restrict, or ban the POPs. Several advantages can be underlined: 1- low sectoral dependance, since all industries are concerned, 2very good data availability among the 145 countries, 3- an important cross-sectional variance in the data. We can also consider that POPs regulation is a de jure measure, since its directly concerns the legislation and not its application. In comparison with de facto indicators often related to performance, the endogeneity bias between environmental standards and levels of productivity is limited 23

\footnotetext{
${ }^{21}$ Alternatively we also built measures of the gap in environmental policies, noted $\zeta_{N S}^{t}=\frac{E_{N}^{t}}{E_{S}^{t}}$, to check our main assumption. A positive sign is then expected.

${ }^{22}$ This measure is preferred to the widely used private abatement costs (Levinson, 2001; Greenstone, 2002; Keller and Levinson, 2002; Fredriksson et al., 2003; Eskeland and Harrison, 2003; Henderson and Millimet, 2007) because they are based on surveys at plant-level data, which are obviously not available for our sample. See Kellenberg (2009) for an interesting discussion on environmental policy data.

${ }^{23}$ see Bazillier, Hatte and Vauday (2016) for a detailed discussion on de jure and de facto measures of environmental regulation.
} 
Effects of Corruption The last vector $\Omega$ takes into account the direct effect of corruption, as suggested by the theory:

$$
\Omega \equiv a_{7} c_{S}^{t}
$$

where $c_{S}^{t}$ is a measure of corruption costs. Following the literature on FDI and our theoretical prediction regarding the direct cost of corruption, we expect a negative sign. To answer our question, "Is a pollution haven also a corruption paradise?" we also check the interaction between the gap in environmental regulation and corruption levels. Following our theoretical results, we expect a negative coefficient for corruption but a positive one for its interactive effect with the gap in environmental regulation, particularly for intermediate-levels of bad governance. An extra set of regressions is performed to refine the results of the interactive effects of corruption, notably by separating countries into different groups.

Good governance is complex to grasp, especially in the case of a panel study. As a result, we are conservative, and to construct an indicator of corruption, we use Kaufmann, Kraay and Mastruzzi's (2010) classical database on institutional quality, available for 209 countries. ${ }^{24}$ This data set contains notations, the lowest one representing poor governance. To directly capture the estimated coefficient of corruption costs, we rescale these notations to obtain that the highest values represent poor governance, while negative values proportionally refer to a low level of corruption.

All the data sources are reported in Table $(8)$ in Appendix B. We also report the descriptive statistics of all the explanatory variables, in Table (9).

Our empirical identification mainly relies on cross-national and cross-sectorial variability, since data for only three years are fully available. All market access indexes vary across countries (x2), sectors and time. Similarly, environmental expenditures also vary over all the dimensions. Concerning regulation on POPs and corruption, we observe an important variation across countries but a small variation across years. However, the environmental performance index presents higher time-variability than the regulation on POPs. Thus, we prefer bilateral variables of controls, to fixed effects even if the parameter estimates are actually not sensitive to the introduction of pair dummies.

\footnotetext{
${ }^{24}$ Kaufmann et al. (2009) process data in order to make cross-country comparisons. All country scores are accompanied by standard errors, which reflect the multiplicity of available data sources (used to build the corruption scores) and the potential differences of opinion among those sources. In order to capture the corruption effect highlighted in the economic model, we use the index of corruption but also conduct regressions after including other governance indicators, in particular, the rule of law. The results are very similar and not reported here.
} 


\section{Results}

\subsection{Pollution haven and market access}

The first set of results is reported in Table (1). Our two main objectives are to stress the role of market access, and to show evidence of a pollution haven effect. The following regressions differ in the variable used to capture environmental policy (regulation on POPs or performance), in the multilateral market access (total or foreign market access), in the way to control for the pair heterogeneity (by observable variables or pair dummies) and finally the nature of the dependent variable (number of affiliates or turnover). 
Table 1: Baseline results

(1) (2)

(3)

$(4)$

$(5)$

(6)

\begin{tabular}{|c|c|c|c|c|c|c|}
\hline \multirow[t]{2}{*}{ Dep variable } & \multicolumn{4}{|c|}{$s_{N S}^{k t}$} & $s_{N S}^{k t}$ & $T_{N S}^{k t}$ \\
\hline & \multicolumn{4}{|c|}{ Pooled $\left(\lambda_{N S}=o b s\right)$} & $\left(\lambda_{N S}=F E\right)$ & $\left(\lambda_{N S}=o b s\right)$ \\
\hline Bilateral MA & 0.091 & 0.087 & 0.094 & 0.120 & 0.073 & 0.093 \\
\hline $\ln \left(M A b_{S N}^{k t}\right)$ & $0.008^{a}$ & $0.008^{a}$ & $0.008^{a}$ & $0.008^{a}$ & $0.008^{a}$ & $0.011^{a}$ \\
\hline MA from the origin & -0.249 & -0.236 & -0.468 & & -0.337 & 0.987 \\
\hline $\ln \left(M A_{N}^{k t}\right)$ & $0.068^{a}$ & $0.070^{a}$ & $0.063^{a}$ & & $0.066^{a}$ & $0.146^{a}$ \\
\hline MA from the destination & 0.888 & 0.856 & 0.830 & & 0.423 & 0.157 \\
\hline $\ln \left(M A_{S}^{k t}\right)$ & $0.060^{a}$ & $0.061^{a}$ & $0.058^{a}$ & & $0.656^{a}$ & $0.019^{a}$ \\
\hline foreign MA from the origin & & & & -0.337 & & \\
\hline $\ln \left(M A f_{N}^{k t}\right)$ & & & & $0.084^{a}$ & & \\
\hline foreign MA from the dest. & & & & 0.428 & & \\
\hline $\ln \left(M A f_{S}^{k t}\right)$ & & & & $0.013^{a}$ & & \\
\hline \multicolumn{7}{|l|}{ Environmental regulation } \\
\hline Env expenditures & 0.551 & 0.549 & 0.542 & 0.475 & 0.646 & 0.431 \\
\hline at the industry-level $\ln \left(E_{N}^{k t}\right)$ & $0.015^{a}$ & $0.014^{a}$ & $0.014^{a}$ & $0.014^{a}$ & $0.014^{a}$ & 0.024 \\
\hline Env. regulation in the origin & 0.046 & & 0.108 & 0.108 & 0.041 & 0.013 \\
\hline at the country-level $E_{N}$ & $0.005^{a}$ & & $0.007^{a}$ & $0.007^{a}$ & $0.006^{a}$ & 0.012 \\
\hline Env regulation in the dest. & -0.032 & & -0.010 & -0.019 & -0.035 & -0.019 \\
\hline at the country-level $E_{S}$ & $0.002^{b}$ & & $0.002^{a}$ & $0.002^{a}$ & $0.002^{a}$ & $0.004^{a}$ \\
\hline Env regulation gap & & 0.375 & & & & \\
\hline$\zeta_{N S}=\frac{E_{N}}{E_{S}}$ & & $0.046^{a}$ & & & & \\
\hline \multicolumn{7}{|l|}{ Corruption effects } \\
\hline \multirow{2}{*}{ Corruption index $c_{S}^{t}$} & -0.101 & -0.097 & -0.047 & -0.079 & -0.756 & -0.058 \\
\hline & $0.025^{a}$ & $0.018^{a}$ & $0.023^{b}$ & $0.025^{a}$ & $0.215^{a}$ & $0.023^{b}$ \\
\hline Inflation model & Logit & Logit & Logit & Logit & Logit & Logit \\
\hline Country-pair $\lambda_{N S}$ & obs & obs & obs & obs & pair_FE & obs \\
\hline Pseudo- $R^{2}$ & 0.82 & 0.82 & 0.82 & 0.82 & 0.88 & 0.83 \\
\hline Log Likelihood & -20543 & -20821 & -20525 & -20709 & -19737 & -35054 \\
\hline Wald Chi-2 & $3468.75^{1}$ & $3149.77^{1}$ & $3447.21^{1}$ & $2943.56^{1}$ & - & $1245.48^{a}$ \\
\hline Likelihood-ratio test & $4.9 \mathrm{e}+05^{1}$ & $4.9 \mathrm{e}+05^{1}$ & $4.9 \mathrm{e}+05^{1}$ & $4.9 \mathrm{e}+05^{1}$ & $4.9 \mathrm{e}+05^{1}$ & $2.07 \mathrm{e}+07^{1}$ \\
\hline Vuong test & $95.20^{1}$ & $95.20^{1}$ & $95.20^{1}$ & $95.20^{1}$ & $95.20^{1}$ & $18.44^{1}$ \\
\hline Overdispersion test (alpha) & $1.185^{1}$ & $1.185^{1}$ & $1.185^{1}$ & $1.185^{1}$ & $1.185^{1}$ & $2.651^{1}$ \\
\hline Zero observations & 6277 & 6277 & 6277 & 6277 & 7902 & 6277 \\
\hline Observations & 10507 & 10507 & 10507 & 10507 & 11869 & 10507 \\
\hline
\end{tabular}

${ }^{a b}$ denote significance at the 1 and 5 level respectively; ${ }^{1}$ denotes the rejection of Null hypothesis at the $1 \%$ level.

Robust standard errors are reported under each coefficient. They have also been confronted with bootstrapped standard errors.

In colums (1) and (2), environmental reg. is captured by POPs regulation, while EPI is used in the other regressions.

When $\lambda_{N S}$ is captured by observable variables, are actually introduced bilateral distances (-), a dummy for common language $(+)$, the differential of tax income (+), GDP per capita $(+)$ and unemployment rates $(-)$.

Concerning trade effects, market access plays a significant role in the location choice of 
multinational firms. All the coefficients are significantly different from zero, regardless of bilateral or multilateral trade openness. As observed from each column, the number of affiliates is significantly influenced by the market access from abroad $\left(\ln \left(M A_{S}^{k t}\right)\right)$. This market access is multilaterally defined which means that European firms easily export to each partner of country $\mathrm{S}$, it is thus the market potential of country $\mathrm{S}$ that created the agglomeration force. This result suggests that firms escape the European regulation but not its market. This argument is also effective for intra-European relocations (i.e. when $\mathrm{S}$ concerns european countries). The same effect is obtained for bilateral market access $\left(\ln \left(M A b_{S N}^{k t}\right)\right)$, a $1 \%$ increase in bilateral market access from $S$ to $N$, fosters relocation of $0.09 \%$ from $N$ to $S$ (e.g. Column 1). Interestingly, this variable does not include third country (i.e. multilateral) effects but directly captures relocation due to the re-importation strategy.

On the contrary, better market access from each European country $\left(\ln \left(M A_{N}^{k t}\right)\right)$ reduces relocation. This illustrates the common tradeoff between relocation and trade, wherein a firm with good market access obtains no benefit by relocating its activities abroad. This result is verified for all specifications (see Columns 1-3).

Column (4) presents the results estimated with a more restrictive definition of market access. Instead of using $\ln \left(M A_{N}^{k t}\right)$ and $\ln \left(M A_{S}^{k t}\right)$ which include domestic as well as foreign market access, we only use the foreign one $\ln \left(M A f_{N}^{k t}\right)$ and $\ln \left(M A f_{S}^{k t}\right)$. The signs and significance of the parameters are consistent with the first set of results. The location choice of multinational firms is thus motivated by the market potential of the new location.

Now, turning to the impact of environmental regulation, we first conduct the estimation based on the regulation for POPs, at country levels $\left(E_{N}, E_{S}\right)$ in column (1) and on the differential $\zeta_{N S}=\frac{E_{N}}{E_{S}}$ in column (2). As expected, we find significant and positive coefficients for the regulation in the origin country $E_{N}$ and for the differential between the regulation levels of the origin and destination $\zeta_{N S}$. The same instrument in the destination country clearly restricts location choices. This opposition in sign between environmental policy at the origin and destination is robust to the use of an alternative index of stringency, namely, the composite indicator of performance. Column (3) presents the results of this alternative estimations and confirms our conclusions.

In addition, we systematically introduce environmental expenditures, at the sectorial level to complete our analysis with a monetary index of environmental policy. The positive relationship between environmental expenditures and relocation is constant among the alternative specifications. Regulation appears as an inducement to leave, showing that the PHH is not a myth. Column 6 reports the results of an estimation in which the turnover of Europeancontrolled affiliates, instead of the stock of affiliates, is regressed. The parameter estimates are consistent with the findings from the first round of regressions. 
To verify that these conclusions are not misleading, we deal with several econometric issues, such as heterogeneity, omitted bias and measurement error. First, the vector $\lambda_{N S}$ aims to control for the sample heterogeneity by capturing specific features of pair countries. In columns 1 to 4, we systematically use bilateral controls, including geographic features (distances), cultural and institutional proximity (a dummy for common language), and socio-economic differences (tax incomes, GDP per capita and unemployment rates). In column 5, we conduct an estimation based on pair dummies instead of observable features. Even if we experience the elimination of important dummies owing to multicollinearity, the main coefficients are maintained, and the conclusions about trade and regulation effects are robust. However, we observe a marked change in the corruption effect. Indeed, all the regressions include an index of corruption abroad. As expected, corruption negatively impacts the location choices, since it represents a significant cost. Once pair dummies are included, the estimated coefficient increases significantly, revealing a potential multicollinearity issue. Based on the theoretical model (Corollary 1) and following the $\mathrm{CPH}$, we consider that, corruption indeed affects both location choices and environmental regulation, especially for intermediate levels of bad governance.

Before testing Corollary 1 and to deepen the prior analysis, we focus on Proposition 1 by analyzing the joint effect of the gap in environmental policy and trade integration. We complete the econometric specification in Equation $(16)$ with an interaction term between bilateral market access $M A b_{N S}$ and the gap in environmental regulation $\zeta_{N S}$. A positive coefficient will confirm the results seen in Figure 1; the wider the gap in regulations, the greater the impetus for relocation due to trade openness. Table 2 only reports the coefficient of this joint effect, all other results are similar.

Table 2: Joint effect of market access and gap in environmental policy

\begin{tabular}{l|c|c}
\hline Dep variable & $S_{N S}^{k t}$ & $T_{N S}^{k t}$ \\
\hline Bilateral market access*env gap $\ln \left(M A b_{N S}^{k t} \zeta_{N S}^{t}\right)$ & 0.103 & 0.133 \\
$R S E$ & $0.011^{a}$ & $0.011^{a}$ \\
\hline${ }^{a}$ denotes significance at the 1 level; The econometric specification is an augmented \\
version of Equation 16 and other coefficients are closed to those \\
reported in columns 3 and 6 of Table 1 .
\end{tabular}

\subsection{Direct and indirect effects of corruption}

Interaction effects As discussed previously, bad governance in the context of a pollution haven is attractive only for intermediate levels of corruption, as suggested by the numerical 
simulations based on the model. It is likely that countries with the worst institutions are not attractive even if they impose very lax environmental regulations. We thus re-estimate the previous model thrice by considering different thresholds of corruption. In concrete terms, we define three separate dummy variables, each of which takes the value 1 for bad governance, moderately bad governance, and good governance.25 These dummy variables are denoted as corrupt $_{S}$ and we assess their interaction with the gap $\zeta_{N S}$. All the other previously used independent variables are also included in the regression but, as the findings are fairly identical, we only report the results of the interaction term in Table (3).

Columns 1 and 3 reveal that the gap in environmental regulation is not attractive at the extreme of the spectrum of governance. In short, the pollution haven hypothesis is neither verified in countries with good governance nor in countries with very bad governance. This certainly explains why many studies consider the PHH to be a myth. But the myth turns out to be true for an intermediate level of governance. Indeed the effect is significantly positive for moderately bad governance.

Table 3: Interaction effects

\begin{tabular}{c|ccc|ccc}
\hline Dep variable & \multicolumn{3}{|c|}{$s_{N S}^{t}$} & \multicolumn{3}{c}{$T_{N S}^{t}$} \\
\hline Country group & Bad & Middle & Good & Bad & Middle & Good \\
$\zeta_{N S}$ corrupt $_{S}$ & -1.342 & 0.110 & -0.012 & -1.803 & 0.590 & 0.534 \\
$R S E$ & $0.124^{a}$ & $0.008^{a}$ & 0.100 & $0.167^{a}$ & $0.161^{a}$ & $0.146^{a}$ \\
\hline
\end{tabular}

${ }^{a}$ denotes significance at the 1 level; The econometric specification is an augmented version of Equation $16 \mathrm{~s}$

We obtain similar results for turnovers, an additional interesting finding being that good governance is now significantly attractive, which is a well known fact in the literature on tax havens (Dharmapala and Hines, 2009). This analysis serves as a preamble to a closer examination of the effects of bad governance on the location choice.

A two-step analysis The first set of regressions emphasizes that while corruption has a negative effect on the whole sample, it can have a positive impact for firms attracted by the gap in environmental regulation in countries with a moderately bad level of governance. This means that in this group of countries, environmental regulation can be endogenously influenced by corruption. Here, we consider this potential endogeneity bias and assess the indirect effect of bad governance on location choices.

\footnotetext{
${ }^{25}$ Each group is classified based on a threshold of the corruption index. If it is less than -1 , the country is considered to be very corrupt (denoted as $b a d$ ). If it is between -1 and 0 , the country is moderately corrupt, and otherwise, it is not corrupt (denoted as good).
} 
Thus this second empirical analysis comprises a two-step procedure involving an instrumentation strategy. To resolve the identification problem, we must find suitable instruments for environmental regulation. The first step consists of decomposing and estimating the environmental regulation prevalent for all partners with "moderately bad governance", namely, countries to which firms relocate a part of their activities, with an instrument measuring environmental regulation and the indirect effect of corruption on these standards:

$$
E_{S}^{t}=\varphi E_{S}^{1971}+\varrho c_{S}^{t}+\iota_{S}^{t}
$$

where as noted previously $c_{S}^{t}$ is the measure of corruption while $E_{S}^{1971}$ is the historical level of the norm and $\iota_{S}^{t}$ an error term. We use the level of regulation on POPs in 1971 as an instrument considering that past levels of this regulation, preceding the 1973-1974 oil crisis, are a good proxy of green vanguard activism preceding and explaining future political mobilization and current environmental laws. ${ }^{26}$ We employ the level of regulation in alternative periods for the robustness checks.

The instrument is relevant if the coefficient $\varphi$ is significantly different from zero. The second econometric condition requires that this variable has no effect on the number of established firms forty years later. Once again, the year 1971 is meaningful for many countries that are now open to FDI, for instance in China, which ushered in the "open door" policy with the creation of Special Economic Zones only in 1978. In later years, the opening up of the economy has been gradual, but it has served as a major turning point, spurring strong investment in infrastructures, tax holidays to attract FDI, and eventually resulting in a fully export-oriented economy dating back to the 1990s. In addition, even if we find that the current level of environmental regulation, $E_{S}^{t}$, is linked to institutions, and precisely, to the level of corruption $(\varrho<0)$, this is not true with past levels of regulation, $E_{S}^{1971}$, which are not correlated with current levels of corruption $\left(\operatorname{cov}\left(E_{S}^{1971} ; c_{S}^{t}\right)=0\right)$. In short, the exogeneity/exclusion condition, which assumes that $\operatorname{cov}\left(E_{S}^{1971} ; \varepsilon_{N S}^{k t}\right)=0$, is well verified. ${ }^{27}$

The introduction of $c_{S}^{t}$ in the first step, is our technical trick to extract the indirect effect of corruption out of the environmental standard when constructing the predicted value of this last variable. Indeed, the predicted value we consider is only $\widehat{\varphi} E_{S}^{1971}$. The data built from $\widehat{\varrho} c_{s t}$ can thus be used to isolate and directly measure the positive effect of corruption with regard to buying laxer environmental laws in a soft kleptocracy interested in attracting dirty firms. More precisely, we perform the second step to explain relocation to a moderately bad

\footnotetext{
${ }^{26}$ The role of a vanguard is particularly important in explaining political change (e.g., Bueno de Mesquita, 2010)

${ }^{27}$ We also use more recent data, namely, the levels of regulation for POPs in 1975 and 1985, in the instrumentation strategy. The results are very similar.
} 
governance environment. The new conditional mean, $\nu_{N S}^{k t}$, is expressed as

$$
\nu_{N S}^{k t}=\exp \left(a_{1}\left(\widehat{\varphi} E_{S}^{1971}\right)+a_{2}\left(\widehat{\varrho}_{s t}\right)+X_{N S}^{t k}+\lambda_{t}+\lambda_{k}\right),
$$

where $a_{1}$ and $a_{2}$ are the coefficients we aim to estimate, and where $X_{N S}^{t k}$ considers the variables used in the previous estimation and nominally reported in Table (4). Because fixed effects are used in prior regressions (in particular, for market access), we computes the bootstrapped standard errors in order to obtain unbiased confidence intervals.

Table 4 reports the results of the two step-estimation. 
Table 4: The Pollution Haven Hypothesis and the role of corruption

\begin{tabular}{|c|c|c|c|c|}
\hline & $(1)$ & $(2)$ & $(3)$ & $(4)$ \\
\hline Dependent variable & \multicolumn{3}{|c|}{$s_{N S}^{t}$} & $T_{N S}^{t}$ \\
\hline Destination group & Baseline & IV & IV & IV \\
\hline Bilateral Market Access & 0.120 & 0.090 & 0.090 & 0.093 \\
\hline $\ln \left(M A B_{S N}^{k t}\right)$ & $0.008^{a}$ & $0.008^{a}$ & $0.008^{a}$ & $0.011^{a}$ \\
\hline Market Access from the origin & -0.337 & -0.188 & -0.188 & 0.987 \\
\hline $\ln \left(M A_{N}^{k t}\right)$ & $0.084^{a}$ & $0.084^{a}$ & $0.084^{a}$ & $0.146^{a}$ \\
\hline Market Access from the destination & 0.428 & 0.214 & 0.214 & 0.157 \\
\hline $\ln \left(M A_{S}^{k t}\right)$ & $0.013^{a}$ & $0.013^{a}$ & $0.013^{a}$ & $0.019^{a}$ \\
\hline Environmental expenditures $E_{N}^{k t}$ & 0.475 & 0.408 & 0.397 & 0.431 \\
\hline at the industry-level & $0.014^{a}$ & $0.018^{a}$ & $0.011^{a}$ & 0.024 \\
\hline Home environmental regulation $E_{N}^{t}$ & 0.108 & 0.085 & 0.085 & 0.013 \\
\hline at the country-level & $0.007^{a}$ & $0.006^{a}$ & $0.006^{a}$ & 0.012 \\
\hline Host environmental regulation $E_{S}^{t}$ & -0.019 & & & -0.019 \\
\hline at the country-level & $0.002^{a}$ & & & $0.004^{a}$ \\
\hline Predicted Host env regulation $\widehat{\varphi} E_{S}^{t-1}$ & & -0.137 & -0.265 & \\
\hline at the country-level & & $0.028^{a}$ & $0.044^{a}$ & \\
\hline Direct effect of corruption $\left(c_{S}^{t}\right)$ & -0.079 & -0.303 & & \\
\hline & $0.025^{a}$ & $0.096^{b}$ & & \\
\hline \multirow[t]{2}{*}{ Indirect effect of corruption $\left(\varrho c_{S}^{t}\right)$} & & & 0.282 & 0.080 \\
\hline & & & $0.060^{a}$ & $0.007^{a}$ \\
\hline \multicolumn{5}{|l|}{ First-step coefficients } \\
\hline IV past regulation $E_{S}^{t-1}$ & 0.334 & 0.334 & 0.334 & 0.334 \\
\hline using POPs regulation in 1971 & $0.020^{a}$ & $0.020^{a}$ & $0.020^{a}$ & $0.012^{a}$ \\
\hline \multirow[t]{2}{*}{ Corruption index $c_{S}^{t}$} & -4.337 & -4.337 & -4.337 & -4.337 \\
\hline & $0.055^{a}$ & $0.055^{a}$ & $0.055^{a}$ & $0.055^{a}$ \\
\hline First-step coefficient of determination & 0.45 & 0.45 & 0.45 & 0.45 \\
\hline Overidentification test p-value & 0.51 & 0.51 & 0.51 & 0.65 \\
\hline First-step Fisher coefficient & $4233.22^{a}$ & $4233.22^{a}$ & $4233.22^{a}$ & $4233.22^{a}$ \\
\hline First-step Root MSE & 7.40 & 7.40 & 7.40 & 7.40 \\
\hline Log Likelihood & $8.3 \mathrm{e}+05^{1}$ & $8.2 \mathrm{e}+05^{1}$ & $7.2 \mathrm{e}+05^{1}$ & $7.6 \mathrm{e}+07^{1}$ \\
\hline Wald Chi-2 & $1719.01^{1}$ & $1688.65^{1}$ & $1674.32^{1}$ & $1306.97^{a}$ \\
\hline Observations & 10507 & 10507 & 10507 & 10507 \\
\hline
\end{tabular}

${ }^{a b}$ denote significance at the 1 and 5 level respectively; ${ }^{1}$ denotes the rejection of Null hypothesis at the $1 \%$ level.

Boostrapped standard errors are reported under each coefficient. They have also been confronted with bootstrapped standard errors.

$\lambda_{N S}$ is captured by observable variables, are actually introduced bilateral distances (-), a dummy for common language (+),

the differential of tax income $(+)$, GDP per capita $(+)$ and unemployment rates $(-)$.

The results of the first step, verify the good performance of the instrumentation strategy. The coefficient of determination for the first step is strong, reaching 0.45 , and the estimated coefficient of our instrumental variable is highly significant, enabling us to reject the null hypothesis of the weak instrument test. The level of regulations for POPs in 1971 positively 
explains the current regulation. Still from this first step, corruption costs significantly reduce the level of regulation, which is in keeping with one of the main assumptions of the theoretical framework, namely, that corruption is viewed as a means to lower environmental standards. Turning to the second step, the most interesting result concerns the impact of corruption, which (as seen previously) is always negative when taking into account the direct measure, $c_{S}^{t}$ (see Columns 1 and 2). However, it becomes positive when considering the indirect effect of bad governance on green regulation $\widehat{\varrho} c_{S}^{t}$ (see Columns 3 and 4).

Thus, the result obtained in the previous section using interaction terms is confirmed here for the second time with a very different method: bad governance, in this group of countries, is attractive owing to its impact on environmental regulation.

\subsection{Sector-based analysis}

The last robustness check is a response to concerns about potentially spurious results specifically the possibility that sectors may experience some other exogenous disturbance affecting location choices. To confirm the $\mathrm{PHH}$ and the $\mathrm{CPH}$, it is important to consider whether the hypothesis is only observed in the context of polluting industries. To do so, we evaluate whether being a polluting or a non-polluting sector affects the impact of environmental norms on location choices. This is a sort of placebo test. We cannot reject the null hypothesis that the coefficients on environmental policy and its interaction with a dummy for polluting sectors are equal to zero. This provides some assurance that the effect of green regulation is significantly linked to the polluting nature of the sectors, and our results are not driven by some other spurious third cause.

Technically,we consider two groups. A reference group is defined as the most highly polluting industries based on their nitrous oxide emissions, and a control group, by less polluting industries ${ }^{28}$ This classification is very similar when sulfur dioxide or carbon dioxide emissions are used as criteria. Then, we generate a dummy variable (polluting sector $=1$ ). We proceed in three ways, first by putting into effect the interaction with the dummy variable identifying polluting industries (column 1 of table 5), by isolating the less polluting industries, and later by conducting sector decomposition (columns 3 and 4). We select two specific sectors: transport equipment, identified as a less polluting sector, and chemicals, which is recognized as a polluting sector.

\footnotetext{
${ }^{28}$ The coking, extraction, energy, chemicals, metallurgy, food processing, and rubber industries are considered as polluting indutries.

The less polluting industries are manufacturing, textile and apparel, transport and equipment, wood, communication and computing.
} 
Table 5: Sector-based analysis

(1)

(2)

(3)

(4)

\begin{tabular}{|c|c|c|c|c|}
\hline Dep variable & \multicolumn{4}{|c|}{$s_{N S}^{k t}$} \\
\hline Sectors & All & Less polluting & Chemicals & Transport equ. \\
\hline Bilateral MA & 0.090 & 0.078 & 0.101 & 0.081 \\
\hline $\ln \left(M A b_{S N}^{k t}\right)$ & $0.008^{a}$ & $0.005^{a}$ & $0.003^{a}$ & $0.005^{a}$ \\
\hline MA from the origin & -0.188 & -0.067 & -0.026 & -0.011 \\
\hline $\ln \left(M A_{N}^{k t}\right)$ & $0.084^{a}$ & $0.014^{a}$ & 0.014 & 0.014 \\
\hline MA from the destination & 0.214 & 0.113 & 0.301 & 0.093 \\
\hline $\ln \left(M A_{S}^{k t}\right)$ & $0.013^{a}$ & $0.010^{a}$ & $0.014^{a}$ & $0.010^{a}$ \\
\hline \multicolumn{5}{|l|}{ Environmental regulation ${ }^{*}$ polluting sector (dummy) } \\
\hline Env expenditures $*$ polluting sector & 0.589 & 0.459 & 0.350 & 0.448 \\
\hline at the industry-level $\ln \left(E_{N}^{k t}\right)$ & $0.017^{a}$ & $0.011^{a}$ & $0.041^{a}$ & $0.051^{a}$ \\
\hline Env. regulation in the origin $*$ polluting sector & 0.118 & 0.008 & 0.138 & 0.098 \\
\hline at the country-level $E_{N}$ & $0.008^{a}$ & 0.011 & $0.019^{a}$ & $0.026^{a}$ \\
\hline Predicted Host env regulation $\widehat{\varphi} E_{S}^{t-1} *$ polluting sector & -0.301 & -0.022 & -0.275 & 0.009 \\
\hline at the country-level $E_{S}$ & $0.040^{a}$ & 0.027 & $0.022^{a}$ & 0.012 \\
\hline \multicolumn{5}{|l|}{ Corruption effects } \\
\hline \multirow[t]{2}{*}{ Indirect effect of corruption $\left(\widehat{\varrho} c_{S}^{t}\right)$} & 0.282 & 0.115 & 0.243 & 0.116 \\
\hline & $0.060^{a}$ & 0.109 & $0.046^{a}$ & 0.109 \\
\hline Pseudo- $R^{2}$ & 0.82 & 0.82 & 0.82 & 0.82 \\
\hline Log Likelihood & $1674.32^{1}$ & -20821 & -20525 & -20709 \\
\hline Wald Chi-2 & $7.2 \mathrm{e}+05^{1}$ & $3149.77^{1}$ & $3447.21^{1}$ & $2943.56^{1}$ \\
\hline Observations & 10507 & 3036 & 566 & 548 \\
\hline
\end{tabular}

${ }^{a b}$ denote significance at the 1 and 5 level respectively;

${ }^{1}$ denotes the rejection of Null hypothesis at the $1 \%$ level.

Robust standard errors are reported under each coefficient.

More Polluting sectors: coking, extraction, energy, chemicals, metallurgy, food processing, and rubber industries

Less Polluting sectors: manufacturing, textile and apparel, transport and equipment, wood, communication and computing industries 
Table (5) presents the last set of results. Column 1 reports the results for the whole sample in which the environmental policy variables interact with the dummy of polluting firms. The model is then re-estimated by considering only the less-polluting sectors, and the estimations are reported in Column 2. At this stage, the PHH is verified since the coefficients of regulation in POPs are strongly significant as far as polluting sectors are concerned, but they become insignificant when the less polluting ones are isolated. The $\mathrm{CPH}$ is also well verified since the coefficient for the indirect effect of corruption is not significant for the less polluting sectors. Now, we proceed to a sector-based analysis, by working only with chemicals firms, which are usually considered as polluting firms (e.g., Millimet and Roy, 2013). Lastly, we focus on transport equipment, which is produced without generating too much pollution. The results from the last group can be interesting because these industries are related to economic growth, thus allowing us to analyze if our environmental variables incorrectly capture other effects (linked to development), which are not our primary interest. Comparisons of the results show that all variables have the same sign when analyzing polluting firms only. The results for the whole sample displayed in the previous section are thus primarily driven by polluting firms.

A closer look at the coefficients of less polluting industries only (Column 2), indicates the similitude with the main results regarding market access, which are still significant. The most striking difference concern the impact of the environmental norms in the destination country, which is no longer significant. Conversely, the impact of environmental policy in the origin country is still surprisingly significant. 29 However, this last check allows us to confirmthe CPH. Indeed, the indirect effect of corruption is not significant when the less polluting industries are only considered. A comparison of the results for the chemicals and transport equipment industries leads to similarfindings: bad governance and laxer environmental norms are only attractive for the chemical sector.

\section{$5 \quad$ Economic significance and policy implications}

Our results are statistically significant, but do they also matter in the economic sense? Using the previous parameters estimates, it may be interesting to shock the data in order to quantify how more stringent environmental regulations in partner countries may affect relocation choices. We first use the results obtained by estimating equation (16) and reported in Table (4) Column 3), to simulate the impact of an effective policy of environmental harmonization in the European Union. We enforce stricter environmental regulation, $E_{S}^{t}$, in European

\footnotetext{
${ }^{29}$ We cannot consider this test as a strict placebo one, since we would need an higher level of disagregation to formally distinguish which are the polluting firms.
} 
countries $S$ (among the EU-27) to raise this regulation to the level of their partners $N$ $E_{N}^{t}$. In short, we cancel out the gap in bilateral environmental regulation in Europe. We consider the parameter estimates after controlling for the indirect effect of corruption, since it captures the two hypotheses: pollution haven and corruption paradise. The predicted number of relocated firms after this shock is far from negligible. The number of firms interested in relocating their activities to these countries after harmonization decreases by $6 \%$. This figure is quite important as it shows that third-country effects have been captured by market access from the origin and from the destination. Taming the PHH in the European context can thus be economically important.

Now, we turn to the second scenario. We previously emphasized that market access is an important determinant of relocation. Here, we study how trade negotiations between Europe and its partners can be useful to negotiate environmental regulations. We present our result for a a carbon tax scenario, that is, we assess the reduction in market access required to compensate the gap in environmental regulation. Although, this is typically a policy of "environmental regulations for trade," it is evident that the manner of computation for this policy is strictly equivalent in our framework to a policy of "trade for environmental regulations," where, for instance, preferential agreements can be enforced with countries willing to abandon their laxer environmental policies. We select key partners, namely, the Maghreb region (Tunisia and Morocco, countries for which the data are available), and China which attract a significant number of European affiliates. This time, we suppose that the removal of the gap in environmental regulation will not affect the number of relocations but will be compensated by a variation in market access to the single European market. We evaluate the equivalent variation in market access needed to obtain more stringent environmental standards from these partners without affecting their attractiveness. Given the current level of relocation, a carbon tax reducing access to the European market by $13 \%$ for firms operating in the Maghreb erases the advantage of the gap in environmental regulations. This protection needs to be considerably higher for China (31\%). Although, analyzing these numbers is outside the scope of this paper, such a high level of tax could imply substantial monetary loss for European consumers.

\section{Conclusions}

The world is not flat; however, countries with heterogeneous institutions have rarely been so integrated. How do polluting firms evolve in this political and economic environment? Do pollution havens exist, and if so, are they also corruption paradises? To tackle these issues, our study proposed a theoretical model and an empirical analysis of the $\mathrm{PHH}$ regarding the 
locations of European affiliates over the period 2007-2009. W found evidence of the positive influence of trade integration magnified by the gap in environmental regulation on the flight of polluting firms to pollution havens have been found. In the current context of globalization, some countries, especially developing and emerging countries with an intermediate level of bad governance, attract dirty firms. Pollution haven and corruption paradise are not theoretical curiosities; they are attractive for some European firms. The European Union and its large market has the potential to bring about some improvements; however, only coordinated policies at the global level for environmental standards, trade integration, and governance can really change the current situation. Owing to the failures of past global collective actions on these subjects, the future looks less bright with validations of the $\mathrm{PHH}$ than without.

\section{References}

[1] Amiti, M. and Javorcik, B.S. 2008. Trade Costs and Location of Foreign Firms in China, Journal of Development Economics, 85(1-2) 2008, pp. 129-149 37 pages / 907 KB

[2] Anderson, J.E. 2005. Trade and Environment. Book Review. Journal of International Economics 65. 523-540.

[3] Anderson, J. E., E van Wincoop, 2003. Gravity with Gravitas: A Solution to the Border Puzzle, American Economic Review, 93 (2003), 170-192.

[4] Baldwin R, and Taglioni D, 2007, Gravity for Dummies and Dummies for Gravity Equations, Journal of Economic Integration, 22-4, p 780-818.

[5] Bazillier, R., Hatte, S. and J. Vauday, 2016. Is Reputation at Stake When Environmentally Responsible Multinationals Invest Abroad? An Empirical Investigation. Working Paper.

[6] Ben Kheder, S.B. and N. Zugravu. 2012, Environmental Regulation and French Firm Location Abroad. Ecological Economics, vol 77, 48-61.

[7] Bosker, M., Brakman, S., Garretsen, H., Schramm, M. 2010. Adding geography to the new economic geography: bridging the gap between theory and empirics. Journal of Economic Geography, pp. 1-31.

[8] Broda C. and D. Weinstein, 2006. Globalization and the Gains from Variety, Quarterly Journal of Economics Volume 121, Issue 2 - May 2006.B.D 
[9] Brunel, C. 2016. Pollution Offshoring and Emission Reductions in European and US Manufacturing, forthcoming in Environmental and Resource Economics.

[10] Brunel, C. and A. Levinson, 2013, Measuring Environmental Regulatory Stringency, OECD Trade and Environment Working Papers, OECD Publishing.

[11] Bueno de Mesquita, Ethan. 2010. \Regime Change and Revolutionary Entrepreneurs." American Political Science Review 104: 446-66.

[12] Cameron, A.C. and Pravin K. Trivedi (1986), "Econometric Models Based on Count Data: Comparisons and Applications of Some Estimators and Tests", Journal of Applied Econometrics, January 1986, Vol. 1, pp. 29-54.

[13] Candau, F. and Dienesch, E. 2015. Spatial distribution of skills and regional trade integration, The Annals of Regional Science, vol. 54(2), pages 451-488.

[14] Cave L.A and G.C. Blomquist, 2008. Environmental policy in the European Union: Fostering the development of pollution havens? Ecological Economics 65, pp.253-261.

[15] Cole, M.A., Elliott, R.J.R., 2005. FDI and the Capital Intensity of "Dirty" Sectors: A Missing Piece of the Pollution Haven Puzzle. Review of Development Economics, 9(4), $530-548$.

[16] Cole, M.A., Elliott, R.J.R. and Fredriksson, P. (2006). Endogenous Pollution Havens: Does FDI Influence Environmental Regulations? Scandinavian Journal of Economics, 108, 1, pp. 157-78.

[17] Cole, M.A. and Fredriksson, P.G. 2009. Institutionalized Pollution Havens. Ecological Economics, 68, 4, pp. 925-1274.

[18] Copeland, B.R., Taylor, M.S., 2003. Trade and the Environment: Theory and Evidence. Princeton University Press, Princeton.

[19] Dam, L, B Scholtens. 2012. The curse of the haven: The impact of multinational enterprise on environmental regulation. Ecological Economics 78. 148-156

[20] Damania, R., Fredriksson P., List J. A., 2003. Trade liberalization, corruption, and environmental policy formation: theory and evidence. Journal of Environmental Economics and Management 46, 490-51.

[21] Dharmapala D and J Hines, 2009. Which countries become tax havens? Journal of Public Economics. Vol 93, Issues 9-10, p 1058-1068 
[22] Dixit A.K. et Stiglitz J.E. 1977. Monopolistic competition and optimum product diversity. American Economic Review 67(3), pp. 297-308.

[23] Djankov S, La Porta R, F Lopez-de-Silanes and A Shleifer (2002). The Regulation of Entry. The Quarterly Journal of Economics, 117 (1): 1-37

[24] Ederington, J., Levinson, A., Minier, J., 2005. Footloose and pollution free. Review of Economics and Statistics 87 (1), 92-99.

[25] Eskeland, G. S. and Harrison, A. E.: 2003, Moving to greener pastures? Multinationals and the pollution haven hypothesis, Journal of Development Economics 70, 1-23.

[26] Esty, D.C., Levy, M.A., Srebotnjak, T., de Sherbinin, A., 2010. Environmental Sustainability Index: Benchmarking National Environmental Stewardship. Yale Center for Environmental Law and Policy, New Haven, Conn.

[27] Fujita, M., Thisse J., 2006. Globalization and the evolution of the supply chain: Who gains and who looses? International Economic Review 47 (3), 811-836.

[28] Fredriksson Per G., List J A, and Millimet D L, 2003. Bureaucratic corruption, environmental policy and inbound US FDI: theory and evidence, Journal of Public Economics, vol. $87(7-8), 1407-1430$.

[29] Greenstone, M. 2002. The impacts of environmental regulations on industrial activity: Evidence from the 1970 and 1977 Clean Air Act amendments and Census of Manufactures. Journal of Political Economy, 110(6), 1175-1219.

[30] Head, K. and Mayer T., 2011, Gravity, Market Potential and Development, Journal of Economic Geography 11(2): 281-294.

[31] Hering, L. \& Poncet, S. 2010. Market Access and Individual Wages: Evidence from China, The Review of Economics and Statistics, MIT Press, vol. 92(1), pages 145-159, February.

[32] Henderson, D.J. and D.L. Millimet (2007), Pollution Abatement Costs and Foreign Direct Investment Inows to U.S. States: A Nonparametric Reassessment, Review of Economics and Statistics, 89, 178-183.

[33] Jug, J. and D. Mirza (2005), Environmental Regulations in Gravity Equations: Evidence from Europe, World Economy, 28, 1591-1615. 
[34] Kaufmann, D., Kraay, A. and Mastruzzi, M., 2009. Governance matters VIII : aggregate and individual governance indicators 1996-2008, Policy Research Working Paper Series 4978, The World Bank.

[35] Kellenberg D K., 2009. An empirical investigation of the pollution haven effect with strategic environment and trade policy. Journal of International Economics. Volume 78 , Issue 2, 242-255

[36] Keller W. and Levinson A, 2002. Pollution Abatement Costs and Foreign Direct Investment Inflows to U.S. States. The Review of Economics and Statistics, vol. 84(4), pages 691-703.

[37] Levinson A., 2001, An Industry-Adjusted Index of State Environmental Compliance Costs, Arik Levinson, in Behavioral and Distributional Effects of Environmental Policy, University of Chicago Press.

[38] Levinson, A. and Taylor, M. (2008), Unmasking the Pollution Haven Effect, International Economic Review, 49 (1), pp. 223-254.

[39] Manderson E, Kneller R, 2012, Environmental Regulations, Outward FDI and Heterogeneous Firms: Are Countries Used as Pollution Havens? Environmental and Ressource Economics, 51(3), 317-352.

[40] Markusen, James R. \& Morey, Edward R. \& Olewiler, Nancy, 1995. "Competition in regional environmental policies when plant locations are endogenous," Journal of Public Economics, vol. 56(1), pages 55-77,

[41] Martin, R., L. de Preux, U. Wagner. 2014. The impact of a carbon tax on manufacturing: Evidence from microdata. Journal of Public Economics 117, 1-14.

[42] Millimet, D. L., Roy, M.: 2013, Empirical Tests of the Pollution Haven Hypothesis When Environmental Regulation is Endogenous. Forthcoming Journal of Applied Econometrics.

[43] Rezza A A. 2013. FDI and pollution havens: Evidence from the Norwegian manufacturing sector. Ecological Economics, Volume 90, Pages 140-149.

[44] Rezza A A. 2014. A meta-analysis of FDI and environmental regulations. Environment and Development Economics. Published online: 14 April 2014.

[45] Redding, S., Venables, A. 2004. Economic geography and international inequality. Journal of International Economics, vol. 62(1): 53-82 
[46] Silva, S., J.M.C. and Tenreyro, Silvana (2006), The Log of Gravity, The Review of Economics and Statistics, 88(4), pp. 641-658.

[47] Smarzynska Javorcik B S, Wei S-J, 2003. Pollution Havens and Foreign Direct Investment: Dirty Secret or Popular Myth? The B.E. Journal of Economic Analysis \& Policy, De Gruyter, vol. 3(2), pages 1-34, December

[48] Vuong, Q. 1989. Likelihood ratio tests for model selection and non-nested hypotheses. Econometrica, 57, 307-334.

[49] Wagner U, C Timmins, 2009. Agglomeration Effects in Foreign Direct Investment and the Pollution Haven Hypothesis, Environmental and Resource Economics Vol. 43 No. 2 (2009), pp. 231-256.

[50] Zeng, D-Z., Zhao, L., 2009. Pollution havens and Industrial Agglomeration, Journal of Environmental Economics and Management. Volume 58, Issue 2, 141-153.

\section{Appendices}

\section{Appendix A: Theoretical model}

\section{Conditions for the general case}

We present the conditions for the full model presented in equation (5), (8), (9) and (10) ensuring that the HQ remain agglomerated in the North. Resolving the equilibrium condition $\pi_{N N}=\pi_{N S}$ yields an explicit expression of the share of plants :

$$
s_{N}^{*}=-\frac{t_{1}-\sqrt{\left.\Gamma\left[b\left(1+b-2 c_{S}\right)+2\left(b g_{1}-g \zeta \phi\right)-(b-1) b \phi^{2}\right)+t_{1}^{2}\right]}}{\Gamma}
$$

with $g=c_{N}-c_{S}, g_{1}=\left(c_{N}-1\right) \zeta \phi, t=b(\zeta-\phi)\left(1-c_{S}+g_{1}\right), t_{1}=t-g \zeta\left(-1+2 \zeta \phi-\phi^{2}\right)$, $t_{2}=(\zeta-\phi)(\zeta \phi-1), \Gamma=2 g t_{2}$.

Lastly, the wage paid to the skilled workers at the HQ cis sourced from the operating profits earned by the plants. To close the model, we analyze $\pi_{N N}=0$ using the number of firms at equilibrium $(19)$ in order to determine the wage of the skilled workers:

$$
w_{N}^{H}=\left[\left(\frac{b / 2}{s_{N}^{*}+\phi s_{S}^{*} \zeta}+\frac{\phi b / 2}{\phi s_{N}^{*}+s_{S}^{*} \zeta}\right)+c_{N}\right]\left(\frac{b}{s_{N}^{*}+\zeta \phi-\zeta s_{N}^{*} \phi}-1\right)^{-1}
$$


The fragmentation of the firm, therefore gives rise to an international transfer of profits from the plant to the HQ. While in Fujita and Thisse (2006) wage does not depend on trade integration, but owing to the differential in the corruption costs accrued to build a plant in the North and in the South, the wage of skilled workers varies with trade costs in our study 30

Lastly, we determine under what conditions the HQ/skilled workers are always agglomerated in the North. Skilled workers decide to stay in the North if their indirect utility is higher there than in the South; that is at spatial equilibrium we have $w_{N}^{H} / P_{N}^{\mu}=w_{S}^{H} / P_{S}^{\mu}$ which is equivalent to $w_{S}^{H}=w_{N}\left(P_{S} / P_{N}\right)^{\mu}$. From $\pi_{S S}^{*}=0$ and $\pi_{N S}^{*}=0$ we compute the following ratio $\nu_{N}^{1-\sigma} / \nu_{S}^{1-\sigma}=\left(c_{N}+w_{N}^{H}\right) /\left(c_{N}+w_{S}^{H}\right)$. Using these two expressions, the condition implying that the relocation of the HQ to the South is not profitable, $\pi_{S S}^{*} \leq 0$, gives $\left(\nu_{S} / \nu_{N}\right)^{\sigma-1}>$ $\left(c_{N}+w_{N}^{H}\right) /\left(c_{N}+w_{N}^{H}\left(P_{S} / P_{N}\right)^{\mu}\right)$ with $w_{N}^{H}$ given in 20$)$ and $P_{S} / P_{N}=\tau^{1 /(1-\sigma)}$ at $s_{N}^{*}=1$. Thus, if the inefficiency of the HQ in the South is high enough agglomeration in the North is always profitable. $\pi_{S N}^{*} \leq 0$ also holds under this condition.

\section{Parametrization}

To distinguish between the North and the South, we use the index of corruption used by Kaufmann, Kraay and Mastruzzi (2010) ${ }^{31}$ All countries with a positive index are considered as southern countries. 32 We use this classification to compute the average measure of the Environmental Performance Index of Esty, Levy, Srebotnjak and de Sherbinin (2010) ${ }^{33}$ We obtain $e_{N}=58.9$ and $e_{S}=49.3$ on which our simulations are based. Regarding the share of income spent on industrial goods, using OECD data, Bosker et al. find that $\mu=0.335$. We follow this estimation and the literature in Economic Geography in general by setting $\mu=0.4$. We also need the elasticity of substitution between varieties, for instance to evaluate $E_{i}=e_{i}^{\sigma-1}$. We set $\sigma=4$ following Broda and Weinstein (2010) who show that the elasticity of substitution between varieties decreased from 6.8 between 1972 and 1988 to 4.0 (with a standard error of 0.5) over the period 1990-2001.

\footnotetext{
${ }^{30}$ Numerical simulations show that with trade integration, the wage of skilled workers first increases and then decreases.

${ }^{31}$ For more details, see our empirical analysis, which describes this index.

${ }^{32}$ In order to capture corruption cost, we rescale the notation of Kauffman et al. (2010) so that the highest value corresponds to the highest level of corruption while the lowest one refers to good governance.

${ }^{33}$ For more details, see our empirical analysis, which describes this index.
} 


\section{Appendix B: Data}

Some figures on Foreign Affiliates Statistics (o-FATS) To complete the descriptive statistics of sub-section (3.3), we report in Table (6) some figures concerning E.U. countries which record more than 1000 affiliates located abroad. Three main variables are reported, the number of firms, the associated turnover and employment.

Table 6: Total number of non European Affiliates and their economic activity, 2008

\begin{tabular}{|l|c|c|c|}
\cline { 2 - 4 } \multicolumn{1}{c|}{} & Nb of firms $(\mathrm{x} 1000)$ & Turnover $(\mathrm{bn} \in)$ & Employment (x1000) \\
\hline Germany & 11.3 & 682 & 2309 \\
\hline France & 10.3 & 443 & 1785 \\
\hline Italy & 7.8 & 142 & 739 \\
\hline Netherlands & 6.1 & 295 & 666 \\
\hline Sweden & 4.2 & 88 & 658 \\
\hline Denmark & 2.9 & n.a. & 250 \\
\hline Finland & 1.5 & 67 & 214 \\
\hline Slovenia & 1.5 & 3 & 47 \\
\hline Belgium & 1.2 & 19 & 110 \\
\hline Austria & 1.0 & 35 & 153 \\
\hline
\end{tabular}

Germany is the biggest contributor in all variables and its plants are present at almost all destinations. The United States' affiliates play a very important role in Germany (41\%), as well as the Netherlands, Italy, Sweden, Finland, and Belgium. Italy has a strong presence in Africa, and the Netherlands ,in South-East Asia. Twenty-one percent of the Netherlands' turnover is recorded by affiliates located in offshore financial centers.

Overdispersion To confirm the choice of the Negative binomial distribution instead of Poisson, we report the summary statistics of the number of affiliates in Table (7) and we plot its distribution in Figure (2):

Table 7: Summary statistics

\begin{tabular}{l|c|c|c|c}
\hline & Mean & Std deviation & Min & Max \\
\hline Nb of European affiliates & 11.77 & 84.23 & 0 & 4217 \\
\hline Turnover & 488.52 & 4946.79 & 0 & 324116 \\
\hline
\end{tabular}


Figure 2: Distribution of the number of affiliates from Europe, 2007-2010

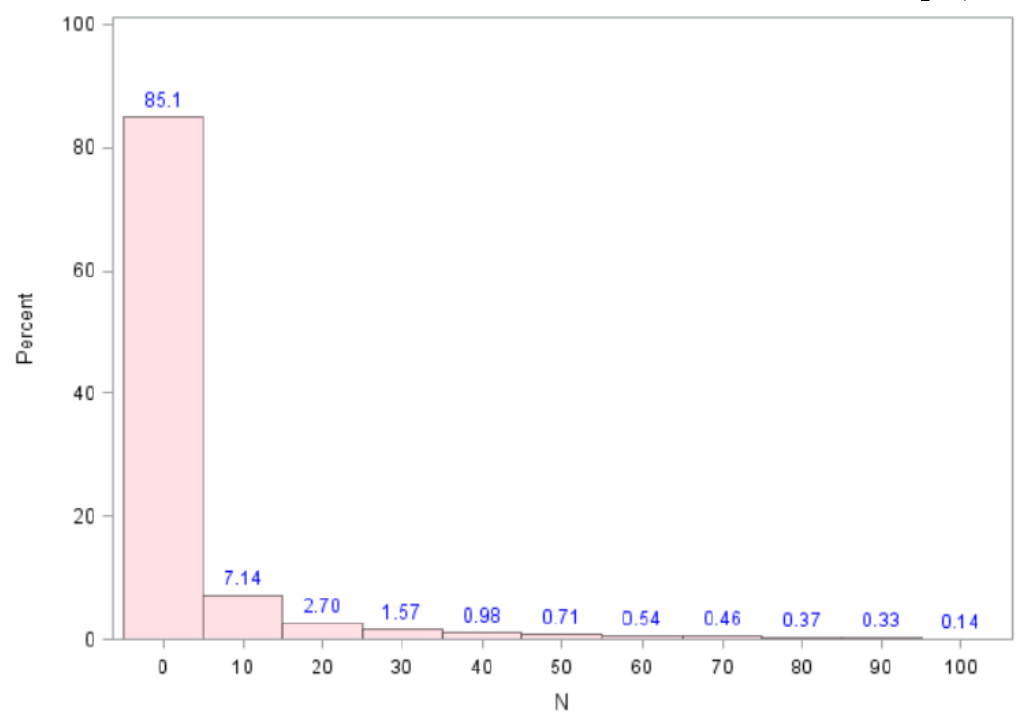

Data sources and summary statistics Table (8) reports the different data sources used in our empirical analysis. The first step (first raw data) refer(s) to the construction of market access, following Redding and Venables' (2004) strategy, which is detailed in Appendix B. The other variables are included in the set of regressors involved in the estimation of Equation (18)

Table 8: Data sources

\begin{tabular}{l|l|l}
\hline First-step & Construction of market access & Source \\
\hline $\begin{array}{l}\text { Bilateral trade } \\
\text { Gravity variables }\end{array}$ & $\begin{array}{l}\text { Imports and Exports at the 2-digit SITC rev2 } \\
\text { Distances, contiguity, borders, language from } \\
\text { in current dollars }\end{array}$ & $\begin{array}{l}\text { UN Comtrade database } \\
\text { Geodist and Gravity (CEPII) } \\
\text { WDI database }\end{array}$ \\
\hline Second-step & Outsourcing equation & \\
\hline Nb of firms & $\begin{array}{l}\text { Firms relocated from European countries } \\
\text { at the industry level Nace rev1 and rev2 }\end{array}$ & FATS (Eurostat) \\
Environment regulation & Env expenditures by industry (Nace rev 1) & Eurostat \\
& Env taxes as share of total taxes & Eurostat \\
Env Performance Index & Global index of env performance & UNEP-Chemicals \\
POPs regulation & Global notation & ITU-ITC \\
Corruption costs & Kauffman, Mastruzzi Kraay index & \\
\hline
\end{tabular}


Table 9: Descriptive statistics of explanatory variables

\begin{tabular}{l|c|c|c|c}
\hline & Mean & Std deviation & Min & Max \\
\hline MA from the origin & 28.652 & 11.158 & 16.032 & 55.026 \\
MA from the destination & 28.118 & 16.435 & 7.589 & 77.461 \\
foreign MA from the origin & 17.722 & 6.607 & 14.747 & 40.455 \\
foreign MA from the dest. & 17.762 & 7.679 & 7.310 & 40.455 \\
Env expenditures & 1410.238 & 3515.732 & 0.14 & 28149 \\
POPs origin & 18.307 & 4.852 & 0 & 21 \\
POPs destination & 15.097 & 7.932 & 0 & 21 \\
POPs origin 1971 & 4.401 & 5.862 & 0 & 18 \\
POPs destination 1971 & 2.328 & 4.128 & 0 & 18 \\
EPI origin & 62.842 & 5.401 & 48.256 & 70.374 \\
EPI destination & 57.427 & 10.194 & 32.543 & 77.993 \\
Corruption index & 0.654 & 1.032 & -1.801 & 2.162 \\
\hline
\end{tabular}

Classications for governance In sub-section 4.2 countries are split into three groups, ordered by their respective corruption scores, with bad, moderately bad or good governance. Given below is each group of countries sorted by their score)

- Bad governance (score <-1): Somalia, Myanmar, Afghanistan, Equatorial Guinea, Turkmenistan, Angola, Iraq, Congo (Democratic Republic of.), Korea (Democratic People's Republic), Papua New Guinea, Chad, Zimbabwe, Uzbekistan, Kyrgyzstan, Congo, Sudan, Venezuela, Libya, Jamaica, Haiti, Cambodia, Tajikistan, Azerbaijan, Russia, Laos, Guinea-Bissau, Côte d'Ivoire, Pakistan, Burundi, Kenya, Yemen, Guinea, Togo, Ukraine, and East Timor.

- Moderately bad governance (score between -1 and 0.5): Bangladesh, Nigeria, Syria, Sierra Leone, Gabon, Cameroon, Ecuador, Central African Rep., Kazakhstan, Honduras, Uganda, Paraguay, Indonesia, Lebanon, Philippines, Comoros, Iran, Mongolia, Tonga, Dominican Rep., Nicaragua, Ethiopia, Benin, Maldives, Moldova, Nepal, Bolivia, Belarus, Niger, Fiji, Mauritania, Cook islands, Niue, Armenia, Gambia, Guyana, Algeria, Senegal, Zambia, China, Guatemala, Liberia, Argentina, India, Albania, Tanzania, Vietnam, Jamaica, Egypt, Eritrea, Mozambique, Sri Lanka, Sao Tome, Malawi, Nauru, Palau, Burkina Faso, Bosnia, Suriname, Mexico, Peru, Thailand, Morocco, Panama, Colombia, Djibouti, Romania, Serbia, Georgia, Bulgaria, Trinidad, Madagascar, El Salvador, Swaziland, Tuvalu, Kiribati, Brazil, Tunisia, Croatia, Belize, Malaysia, Italy, Greece, Ghana, Saudi Arabia, Turkey, South Africa, Samoa, Rwanda, Latvia, Macau, Lithuania, Lesotho, Jordan, Namibia, Bahrain, Slovakia, Seychelles, Kuwait, Grenada, Vanuatu, Hungary, Oman, Czech republic, Poland, and Cuba. 
- Good governance (score >0.5): Korea, Taiwan, Mauritius, Costa Rica, Israel, Dominica, Cape Verde, Bhutan, Guam, Netherlands Antilles, Virgin Islands, Botswana, Malta, Estonia, Brunei, Cyprus, United Arab Emirates, Spain, Slovenia, Portugal, Saint Kitts and Nevis, Saint Vincent, Aruba, Cayman Islands, Greenland, Uruguay, Saint Lucia, United States of America, Barbados, Anguilla, Antigua and Barbuda, Bermuda, Japan, Bahamas, Chile, France, Belgium, United Kingdom, Qatar, Germany, Liechtenstein, Ireland, Austria, Hong Kong, Norway, Luxembourg, Australia, Switzerland, Canada, Iceland, Netherlands, Singapore, Finland, Sweden, New Zealand, and Denmark.

\section{Market access, following Redding and Venables' (2004) approach}

With regard to the explanatory variables, let us start the description with the indicator of trade integration. We use an indirect measure taken from a gravity equation. Direct measures such as tariffs are indeed not relevant since the FATS database includes activities (e.g., services) for which tariffs represent only a small fraction of trade costs.

Based on Redding and Venables (2004), our empirical investigation is a twofold procedure, which consists of estimating a gravity equation with fixed effects and using the results to construct price indexes. The gravity equation is estimated using a PPML estimator ${ }^{34}$ and country-level fixed effects to control for invariant importer-specific and exporter-specific characteristics. This equation is estimated in cross-section, for each industry and each year reported in our sample. The assumptions layered in the gravity equation of Anderson and van Wincoop (2003) are only relevant for a cross-section data set. 35 Thus, we need to estimate this equation in cross-section in order to obtain time-varying market access through different coefficient estimates.

$$
X_{i j}=\lambda \ln \tau_{i j}+a_{i} \ln F X_{i}+a_{j} \ln F M_{j}+e_{i j}
$$

where $F X_{i}$ and $F M_{j}$ are fixed effects to control for a country's market and supply capacity. Note that we use the indices $i$ and $j$ instead of $N$ and $S$ because we use trade data for all trading partners and not only countries recorded in the FATS database. The following is the

\footnotetext{
${ }^{34}$ Following the work of Silva and Tenreyro (2006), the use of pseudo-maximum likelihood estimators (Poisson and derivative econometric models) is justified for treating heteroskedasticity and dealing with the presence of zero trade values.

${ }^{35}$ Indeed, the particular normalization of Anderson and van Wincoop $\left(\Omega_{i}=\lambda P_{i}\right.$, where $\left.\lambda=1\right)$ is incorrect for panel data applications, as Baldwin and Taglioni (2007) have explained and proved with a simple application for three countries and a time dimension.
} 
bilateral expression of market access is following

$$
\widehat{\phi_{i j}}=\underbrace{\left[\left(\exp \left(F M_{i}\right)\right)^{\widehat{a_{i}}} \tau_{i i}^{\widehat{\lambda}}\right]}_{\text {Domestic }}+\underbrace{\left[\left(\exp \left(F M_{j}\right)\right)^{\widehat{a_{j}}} \tau_{i j}^{\widehat{\lambda}}\right]}_{\text {Foreign }}
$$

in which $\widehat{a_{i}}, \widehat{a_{j}}$, and $\widehat{\lambda}$ are the parameter estimates of the PPML regression for each cross section. It appears from Equation (22) that domestic market access can be distinguished from foreign market access. In this equation, bilateral trade $\operatorname{costs} \tau_{i j}$ take the following common specification

$$
\tau_{i j}=d_{i s t_{i j}} \exp \left[Z_{i j}\right]
$$

where $Z_{i j}$ is a vector of dummies characterizing bilateral trade barriers, such as contiguity. Turning to internal trade costs $\tau_{i i}$, we follow Redding and Venables (2004) by expressing internal trade costs as a function of internal distances, computed for a circular country, as it follows:

$$
\begin{aligned}
\tau_{i i}^{1-\sigma} & =\operatorname{dist}_{i i}^{\frac{1}{2} \widehat{\lambda}} \\
\text { dist }_{i i} & =0.66\left(\frac{\text { area }_{i}}{\pi}\right),
\end{aligned}
$$

where area $_{i}$ is the surface in $\mathrm{km}^{2}$.

\section{Appendix C Alternative estimators}

The following table reports the parameter estimates obtained with alternative estimators. Our core strategy is to use a zero-inflated model based on a negative binomial distribution (ZINB), to deal with the excess of zeros and overdispersion. However, we test here how our coefficients are sensitive to other models. Three alternatives are used: an hurdle model, a zero-inflated one based on a Poisson distribution (ZIP) and finally, a pseudo-maximum likelihood strategy (PPML), commonly used for count data, suffering from heteroskedasticity. If results are quite similar, coefficients are all slightly overestimated compared to ZINB. Overdispersion tests lead us to choose the negative binomial distribution instead of Poisson in our core strategy. Then, the difference between ZINB or hurdle models is not very significant. 
Table 10: Alternative estimators - Baseline Equation

(1)

(2)

(3)

(4)

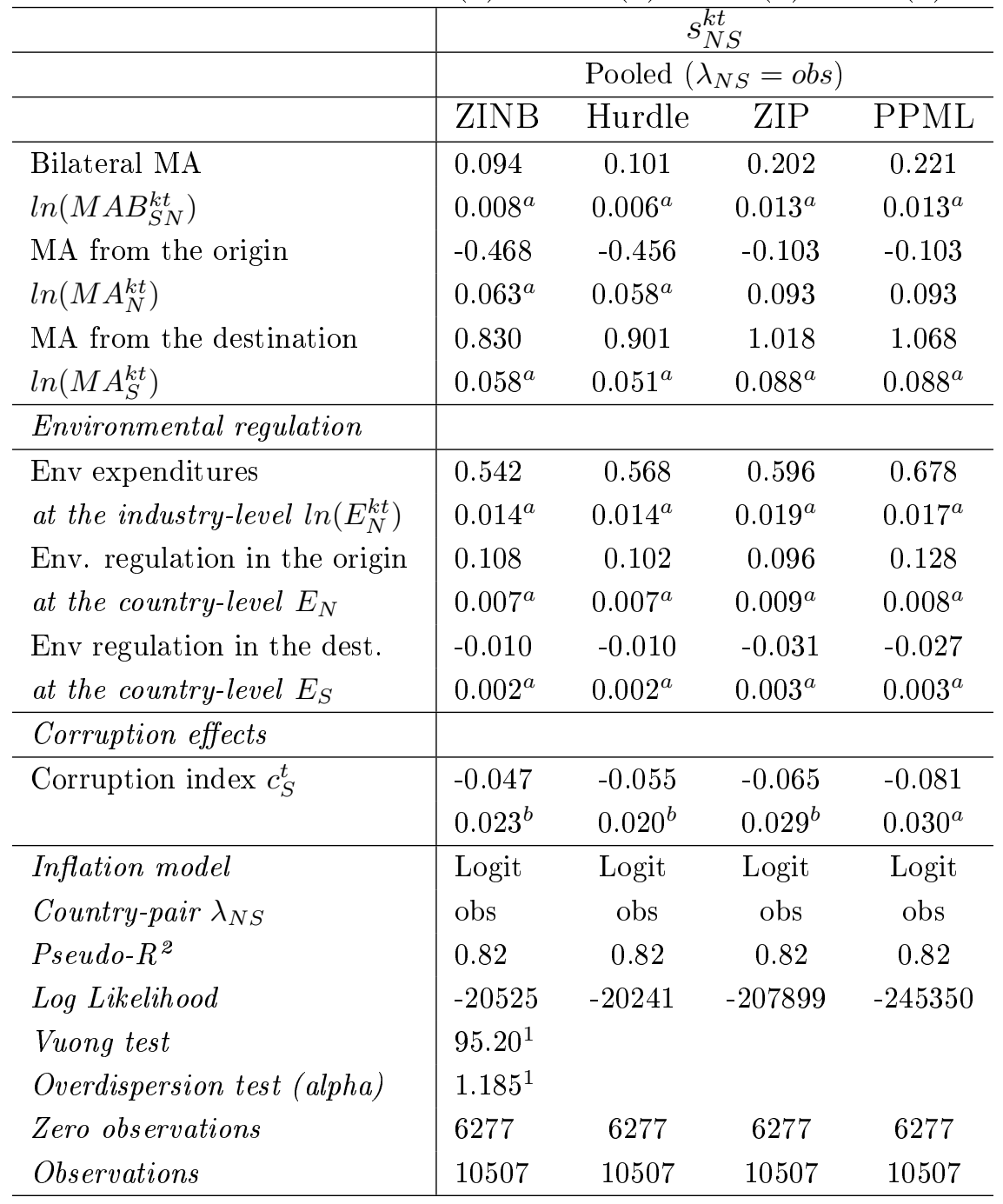

${ }^{a b c}$ denote significance at the 1, 5 and $10 \%$ level respectively;

Robust standard errors are reported under each coefficient. 